\title{
Mismatches at the syntax-semantics interface: The case of non-finite complementation in American Norwegian
}

\author{
Michael T. Putnam ${ }^{1,2}$ and Åshild Søfteland ${ }^{3}$ \\ ${ }^{1}$ Penn State University, GSLL \& Linguistics, 239 Burrowes, University Park, PA 16802, USA \\ ${ }^{2}$ University of Greenwich, Centre for Research \& Enterprise in Language (CREL), London SE10 9LS, UK \\ ${ }^{3}$ Høgskolen i Østfold, F1-088, Halden, Norway \\ Email for correspondence: mike.putnam@psu.edu
}

(Received 12 October 2020; revised 27 May 2021; accepted 28 May 2021; first published online 09 July 2021)

\begin{abstract}
Non-finite complementation strategies found in American Norwegian (AmNo) (made available by the Corpus of American Nordic Speech (CANS)) reveal unique and diverging patterns when compared to both standard and dialectal Norwegian and English. We argue in this paper that the majority of these divergent structures are the result of overextension (Rinke \& Flores, 2014; Rinke et al., 2018; Putnam \& Hoffman, 2021; Kupisch, 2014), where heritage language speakers produce structures that differ from both grammars in an attempt to generate forms that are distinct from the more dominant language. Our treatment of these nuanced structures in AmNo shows that this heritage grammar significantly restricts bare (or naked) TPs (Situations) serving as non-finite complements. To avoid bare TP-complements, AmNo has developed two distinct, yet related strategies, (1) reducing non-finite complements to $v$ Ps (Events), or (2) incorporating an additional element, a preposition, to ensure that the non-finite complement functions as the object of a preposition. We analyze this latter strategy as an instance of the emergence of structural salience (Polinsky, 2018) in the syntax of AmNo and suggest that this variation is best understood as a syntax-semantics interface phenomenon.
\end{abstract}

Keywords: Heritage language syntax; Syntax-semantics interface; American Norwegian; Non-finite complementation

\section{Introduction}

A consistent and pervasive narrative in the literature on the syntactic properties of heritage languages is that while certain domains, such as morphology, are more susceptible to change and attrition, the core properties of syntax remain unaffected both in acquisition and development across the lifespan (Lohndal, 2021; Putnam et al., 2021; Polinsky, 2018; Polinsky \& Scontras, 2020; Lohndal et al., 2019). If and when syntax is affected in heritage grammars, it is usually in connection with interface phenomena, such as the syntaxdiscourse interface (Sorace, 2011; Leal et al., 2014; Hoot, 2017), or it concerns the 
linearization of elements, such as variation in verb-second (V2) phenomena (Arnbjörnsdóttir et al., 2018; Kühl \& Petersen, 2018; Westergaard \& Lohndal, 2019). The prevailing view is that core elements of grammar related to the syntax of heritage languages remain largely unaffected through the course of life, whereas interface properties with other domains of grammar are more vulnerable, subject to attrition and restructuring.

This paper challenges the strongest version of this aforementioned long-standing narrative. Here we demonstrate that complementation, which is largely considered to be intimately connected to core syntactic principles and operations, has been altered to some degree in American Norwegian (AmNo). AmNo is the language of Norwegian immigrants spoken predominantly in the American Upper Midwest since the 1850s. The language, which could be said to contain a mixture of features from multiple variants of vernacular Norwegian since the speakers have different dialectal backgrounds, ${ }^{1}$ is now moribund, with the eldest generation representing the last highly proficient speakers. Here we make extensive use of the Corpus of American Nordic Speech - CANS (Johannessen, 2015), discussing in detail the structure of certain syntactic innovations that occur across the CANS-data. ${ }^{2}$ In particular we draw attention to structural nuances involving the complementation of non-finite clauses that are likely not due directly to encroachment from the dominant societal L2 (English). The examples in (1)-(5) below are representative samples of non-finite complementation patterns that exhibit these nuanced structures - where (1) and (2) follow standard patterns (in this article represented by the written standard 'Bokmål'), (3) could stem from (older, rural) dialectal patterns, but (4) and (5) are not considered to be autochthonous to either standard Norwegian or any of its dialectal variants. (The examples are rendered in the orthophonic transcription from CANS, and 'Outlook-06gm' etc. refers to the different speakers in the corpus, see $\$ 4$ for details.)

(1) je har inngentinng å jøra hær i biin (Bokmål: å) I have nothing INF do here in town.DEF 'I have nothing to do here in town.'

(Outlook-06gm)

(2) $\quad$ i $\quad$ e fø gammall ti $\quad$ a reise (Bokmål: til å) I am too old PRP INF travel 'I'm too old to go.'

(Hatton-02gm)

(3) åh re æ så gått te kåmma heim att (Bokmål: å) oh it is so good INF come home again 'Oh, it's so good to come home again'

(Sunburg-11gk)

(4) je har leRRt te å læsa no nåRsk (Bokmål: only å) I have learned PRP INF read some Norwegian 'I have learned to read some Norwegian.'

(Fargo-02gm)

(5) nårr je var stor nåkk å tjøre bannd'lvægen (Bokmål: til å) when I was big enough INF drive bundle-wagon 'When I was big enough to drive bundle wagon.'

(Decorah-02gm) 
In the control infinitive construction in (4), Bokmål only requires the infinitive marker $a$ to head this non-finite clausal complement, while in the AmNo example we see the inclusion of the preposition te. The construction in (5) exhibits the opposite structure, here Bokmål requires the preposition ('til' in written language) in addition to the infinitive marker $\stackrel{a}{a}$ before the non-finite complement, while the preposition is not included in the AmNo example.

In this study, we present evidence that some speakers of AmNo have (tacitly) developed an innovative strategy that prevents the selection of 'bare' TP-non-finite complements. These complements cannot appear 'naked' and must either be reduced to $v$ Ps or be 'covered up' by a preposition (see $\$ 5$ for an in depth treatment). This pattern in the AmNo-data shows a trend towards overextension (a.k.a. hyperextension), where these speakers produce outputs that sound more 'Norwegian-like' (i.e., those that are 'covered' with both a preposition and the infinitive marker $\stackrel{a}{a}$ ), creating nuances that are not attested in Bokmål or any known source dialects of Norwegian.

Hyperextension is a well-documented phenomenon discussed in the literature on heritage language grammars and contact linguistics more generally (Rinke \& Flores, 2014; Rinke et al., 2018; Putnam \& Hoffman, 2021; Kupisch, 2014); however, in the majority of these previous studies the empirical focus has been on morphosyntax. A recent study by Perez-Cortes et al. (2019) showed that in connection with breakdowns in the morphosyntactic marking of subjunctive mood in heritage Spanish (corresponding with lower levels of proficiency), participants who produced highly variable morphosyntax also exhibited a tolerance (to some degree) of accepting Exceptional Case Marking (ECM) structures. Although acceptable in English, ECM-predicates, which only consist of a TP and their accompanying non-finite complement clauses are not licensed in Spanish, which require all non-finite complement clauses to be CPs. ${ }^{3}$ We adopt the position that this behavior in the study conducted by Perez-Cortes et al. (2019) can be classified as instances of syntaxsemantics interface mismatches, making the case once again for the distinction between principally 'core' (i.e., syntactic) and 'peripheral' (i.e., interface) components in the faculty of human language.

This paper adheres to the following structure: In $\$ 2$ we review the distribution and underlying structure of infinitive markers and non-finite complements more generally in both English and Norwegian. After this brief overview, we introduce our primary research questions and hypotheses in $\$ 3$ before moving on to our extensive review of instances of non-finite complementation in AmNo in $\$ 4$. Here we illustrate the strong tendency in AmNo to avoid naked TPs, which results in the reduction of non-finite complement clauses to $\nu \mathrm{Ps}$, or the addition of a preposition to faciliate a CP-like structure. In the case of this later scenario, we provide an analysis of hyperextension in AmNo in $\$ 5.1$ along the lines of Polinsky’s (2018) proposal of the emergence of structural salience in the syntax of heritage language grammars. The over-application of prepositions to conceal bare TPs signals the presence of non-finite complement clauses in AmNo (in most environments). In $\$ 5$ we explicate the key elements of our analysis of complementation, highlighting essential similarities and differences that exist among English, Bokmål (written standard Norwegian), and dialectal variants of Norwegian. Integrating proposals by Wurmbrand $(2001,2014)$ and Wurmbrand \& Lohninger (to appear) into our 
own, we pursue an approach to syntactic complementation that permits syntaxsemantics mismatches. In our analysis we apply a Minimalist treatment of clausal architecture and complementation. In particular, we adopt a view of clausal architecture as principally containing tripartite substructures divided into Propositions, Situations, and Events, based on the terminology used by Ramchand \& Svenonius (2014). This allows for semantically TP-like structures (i.e., Situations) that can appear as CP-structures. One of the factors that we use to establish the structure of non-finite complements involves the placement of infinitive markers in English and Norwegian. This paper concludes in $\$ 6$.

\section{Infinitive markers in English and Norwegian}

In this section we explicate the differences and similarities found in the distribution of infinitive markers in standard English (to), Bokmål $(\stackrel{a}{a})$, and dialectal varieties of Norwegian. There is a great deal of variability concerning the structural distribution of Infinitival markers cross-linguistically as well as questions pertaining to their categorical status. With respect to the status of Infinitival elements, it is perhaps disingenuous to label these items as (exclusively) representing the morphosyntactic spell out of the absence of tense in a clause (Holmberg, 1986; Johnson \& Vikner, 1994; Christensen, 2007). ${ }^{4}$

Any systematic treatment of the distribution of infinitive markers in English and Norwegian must grapple with the fact that there does not appear to be one single designated structural position in which these elements can occur. The existence of split infinitives in English (6) and in Bokmål (7) and (8) can be adduced as support for this claim:

(6) a. The crew of

b. The crew of where no space where no spaceship has spaceship has

the the U.S.S. gone gone before.

(7) a. Han liker å bare lese bøker. he likes INF only read books 'He likes to only read books.'

b. Han liker bare å lese bøker. he likes only INF read books 'He only likes to read books', or 'He likes to only read books.'

[Bokmål]

(8) a. Jeg lovte å ikke spise is. I promised INF not eat ice-cream

'I promised to not eat ice cream.'

b. Jeg lovte ikke à spise is.

I promised not INF eat ice-cream

'I didn't promise to eat ice-cream' or

'I promised to not eat ice cream.'

[Bokmål] 
A second piece of evidence in support of the unfixed and variable placement of infinitive markers can be found in the contrast between non-finite clauses that permit exceptional case marking (ECM) (9a) and those that license a PRO subject (9b):

(9) a. John expects $[\mathrm{TP}$ her to win the game].
b. Johni expects $\left[\mathrm{CP} \mathrm{PRO}_{\mathrm{i}}\right.$ to win the game].
[Control]

The underlying structural differences between ECM-predicates and their control counterparts in 2 indicate that to can appear in multiple positions. ${ }^{5}$ We accept this as evidence that these elements are realized, or spelled out, in different structural positions. We elaborate further on the implications of this below in $\$ 2.1$ where we discuss the details surrounding ECM-predicates in Bokmål (Lødrup, 2008; Wurmbrand \& Christopoulos, 2020), and argue that infinitive markers and the structure required for hosting ECM-predicates (i.e., TP) are restricted.

Third, Faarlund $(2015,7)$ notes the existence of Double infinitive Marker constructions on Norwegian websites (also in edited texts):

Trenger unnskyldning for $\mathbf{a}$ ikke $\stackrel{\circ}{a}$ drikke på byen.
need
'[I] need an excuse for not drinking when going out.' (VG Debatt)

Faarlund cites a substantial number of representative examples of these constructions to demonstrate that they are not merely performance errors (more on these in $\$ 2.1$. In the subsections to follow, we take a closer look at the distribution of infinitive markers in standard English, Bokmål, and dialectal Norwegian; however, even at this juncture, we can see that proposing a set position for infinitive markers crosslinguistically is futile. In line with proposals put forward by Christensen (2007), Faarlund $(2007,2015,2019)$, and Wurmbrand $(2001,2014)$, we assume that infinitive markers in the languages and dialects under investigation here are lexicalized functional heads. ${ }^{6}$ Furthermore, we propose that infinitive markers are born as functional heads in the 'first phase' $\left(\nu \mathrm{P}_{\mathrm{INF}}\right)$ and may undergo head movement to $\mathrm{T}$ or Fin, as illustrated in Figure 1.

The derivational account adopted here synthesizes previous analyses that assumed that infinitive markers are required to appear in Infinitival $v$ (Fukuda, 2012), in some aspectual projection (Travis, 2000), in T (Stechow \& Sternefeld, 1988; Faarlund, 2015), or in C (Giusti, 1986, 1991;Wilder, 1988) cross-linguistically. ${ }^{7}$ As we explicate below, a second important aspect of our treatment of the structure of non-finite complementation concerns the placement of til. Agreeing with an anonymous reviewer, although at first glance it may be difficult to pinpoint the exact structural position of $t i l$, we provide evidence throughout the remainder of this paper that it is a preposition that can license non-finite complements as objects (Lødrup, 2002; Svenonius, 2021). In the remainder of this section, we focus on the placement of Infinitival markers and the underlying structure of non-finite complements in Bokmål and dialectal Norwegian. 


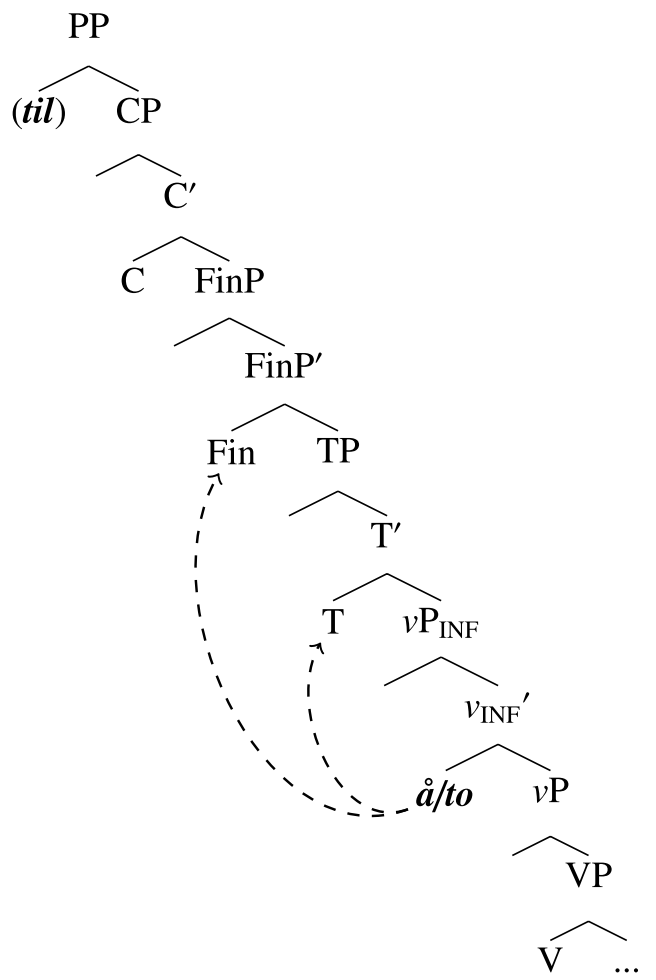

Figure 1. Potential positions of infinitive markers (based on Christensen (2007)).

\subsection{Infinitive markers in Norwegian}

Similar to English, Norwegian licenses control predicates (11) and ECM-verbs (12). In the control predicate example, the infinitive marker $\stackrel{a}{a}$ appears in $\mathrm{C}$, however, in the ECM-predicate $\stackrel{a}{a}$ is not realized.

(11) Erik håper å PRO kunne komme. Erik hopes INF pro can.INF come 'Erik is hoping to be able to come.' (Faarlund, 2019, 245)

(12) Vi hørte henne grå te pårommet sitt. we heard her.ACC cry in room.DEF REFL.POSS 'We heard her crying in her room.' (Åfarli \& Eide, 2003, 175)

Wurmbrand \& Christopoulos (2020) explain that there are two types of ECM in Germanic languages; ECM1 and ECM2 (the examples in (13) are from Wurmbrand \& Christopoulos (2020, 393)). ECM1-predicates appear in all Germanic languages with causative and perception verbs (13a). ECM1-predicates always occur without an 
infinitive marker and syntactically appear as an Event, i.e., a $v$ P. In contrast, ECM2predicates and their accompanying syntactic configurations show some variation regarding the placement of the infinitive marker (13b). Germanic languages show variability with respect to whether or not they license ECM2-predicates.
a. I saw/let
him steal my ice cream.
b. Leo believes/expects me to like ice cream.
[ECM1]
[ECM2]

Norwegian does not license ECM2-predicates with predicates such as say/claim and believe, and only licenses them in a restricted sense with consider and expect. Taking a closer look at the restricted use of expect as an ECM2-predicate, Lødrup (2008) maintains that ECM-subjects in Norwegian need to be dislocated - via V2-movement or other operations - and that their interpretation is restricted to embedded individual-level predicates - so that an example like (14) would be ungrammatical:

$$
\begin{aligned}
& \text { *Jeg forventer ham å drepe musen. } \\
& \text { I expect him INF kill mouse.DEF } \\
& \text { Intended: 'I expect him to kill the mouse.' } \\
& \text { (Wurmbrand \& Christopoulos, 2020, 394) }
\end{aligned}
$$

It is important to note that, according to Lødrup $(2002,2008)$, there are a number of restricted contexts in which Bokmål can (marginally) license ECM2-predicates, for example, with the predicates consider and expect, see (15).

(15) Ingen forventer lærere a være perfekte.
nobody expects teachers INF be perfect
'Nobody expects teachers to be perfect.'
(Lødrup, 2002, 3)

[ECM2]

According to Lødrup (2002, 2008), ECM2-subjects show a strong tendency to be dislocated, meaning that if the subject remains in the expected subject position, it is usually ill-formed or unacceptable. ECM2 in Bokmål is additionally restricted to individual-level predicates. Therefore, English and Norwegian show a noticeable contrast in their ability to license ECM2-type predicates, which we explicate in Table 1 (abbreviated from Wurmbrand \& Christopoulos $(2020,395)) .^{8}$

We interpret these results as an indication that Situations (TP) have a much more restricted distribution as potential non-finite complements in Norwegian (when compared with English). There are, however, two non-finite complements in Bokmål that license a TP. Raising predicates such as antas 'is believed' in (16), evidence that T can host $\stackrel{a}{\mathrm{a}}$. (Given the non-colloquial status of these instances of raising, structures like (16) will be absent or Infrequent in spoken language corpora such as CANS, LIA, and NDC that we will mention later.)

(16) Rotta antas å ta seg inn gjennom et vindu. rat.DEF is.believed INF take REFL in through a window 'The rat is believed to come in through a window.' (Åfarli \& Eide, 2003, 169) 
Table 1. ECM in English and Bokmål

\begin{tabular}{|c|c|c|c|c|c|}
\hline \multirow[b]{2}{*}{ Language } & \multirow[b]{2}{*}{$\overline{E C M 1}$} & \multicolumn{2}{|c|}{ ECM2 } & \multirow[b]{2}{*}{ consider } & \multirow[b]{2}{*}{ expect } \\
\hline & & say/claim & believe & & \\
\hline English & $\checkmark$ & 凶 & $\checkmark$ & $\checkmark$ & $\checkmark$ \\
\hline Bokmål & $\checkmark$ & $\otimes$ & 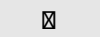 & restricted & restricted \\
\hline
\end{tabular}

Although due to space restrictions we do not investigate the properties of raising in AmNo in any detail, an anonymous reviewer points out their relevance in two particular domains; namely, (i) regarding the multifunctionality of til and (ii) the object status of non-finite clauses. The diverse behavior of til is manifest in at least two different environments that are relevant for analyses of non-finite complements in Norwegian; til can be used (i) as the head of a more regular PP with infinitival complement (cf. 17a) paraphrased in different ways in (17b)-(17d), and (ii) as a functional head in Infinitival clauses with subject raising (cf. (18-a), paraphrased in different ways in (18b)-(18d); data from Lødrup (2002)). Example (17c) in particular shows that non-finite complement clauses can appear as the object of a preposition in Bokmål (thus further justifying the status of til as a preposition):
a. Jeg vil gjerne bidra til å redde salamanderen. I will gladly contribute PRP INF save newt.DEF 'I will gladly contribute to save the newt.'
b. Jeg vil gjerne bidra til dette. I will gladly contribute PRP this 'I will gladly contribute to this.'
c. Til à redde salamanderen vil jeg gjerne bidra. PRP INF save newt.DEF I will gladly contribute 'I will gladly contribute to save the newt.'
d. $\AA$ redde salamanderen vil jeg gjerne bidra til. INF save newt.DEF will I gladly contribute PRP 'I will gladly contribute to save the newt.'

[Bokmål]

(18)
$\begin{array}{llllll}\text { a. Han } & \text { ser } & \text { ut } & \text { til } & \text { a } & \text { sove. } \\ \text { he } & \text { looks } & \text { out } & \text { PRP } & \text { INF } & \text { sleep }\end{array}$
'He seems to sleep.'
b. ${ }^{\star}$ Han ser ut til dette.
c ${ }^{*}$ Til å sove ser han ut.
d. ${ }^{\AA}$ sove ser han ut til.

[Bokmål]

The observation that the raising of the entire non-finite complement to the CP-layer (supported by contemporary analyses of V2; Vikner (2020)) in examples (17-c) and

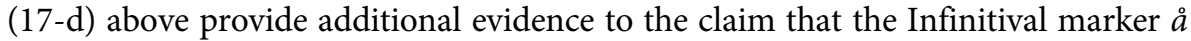
appears in Fin (in the CP-layer) in these examples. The preposition til plays an important role in our analysis of non-finite complements in AmNo and, as established above, we treat $t i l$ (and te in dialectal Norwegian) uniformly as a preposition 
(when it is not functioning as an infinitive marker on its own, cf. \$2.2) (See also Kalm (2016) for a diachronic analysis of $t i l+\stackrel{a}{a} /$ at in Swedish).

Returning to our discussion on the realization of infinitive markers, Faarlund (2015) provides additional evidence that T also serves as a licit host of $\stackrel{a}{\text { in his treat- }}$ ment of double infinitive markers, as shown in (19) (written Norwegian on the WWW).

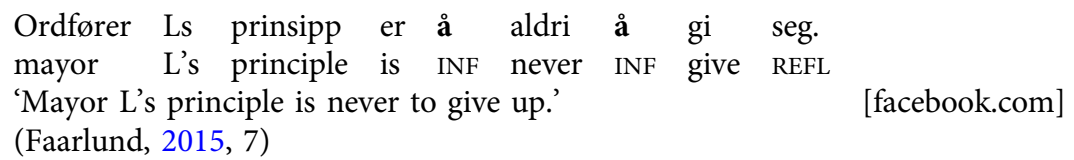

Sentences containing split infinitives further demonstrate the need for three positions for infinitive markers in Norwegian. Christensen (2007) provides examples (from the written standard Nynorsk) that illustrate the optional $v_{\mathrm{INF}} \rightarrow$ T movement of $a$ in (20a) and (20b), as well as the option of the movement chain of $v_{\mathrm{INF}} \rightarrow \mathrm{T} \rightarrow \mathrm{C}$ in (20c) and (20d). ${ }^{9}$ The relevant sentence adverbials appear in italics, the infinitives underlined, and the infinitive markers in bold.
a. Begge desse tinga var nok med på å redusere brannen til both these things were probably with on INF reduce fire.DEF to kun a gjelde garasjen. only INF cover garage.DEF

'Both of these things probably played a part in containing the fire to the garage.'

$\begin{array}{lllllll}\text { b. Det er viktig } & \text { a } & \text { framleis gjere det vi kan. } \\ \text { it is important } & \text { INF still } & \text { do that we can }\end{array}$ 'It is important to keep doing what we can.'
c. For ikkje å spara på kreftene for not INF save on strengths.DEF 'In order not to save strength.'

d. Han oppmoda representantane til å ikkje binda seg opp i he encouraged representatives.DEF to INF not bind REFL up in kroner og øre. crowns and pennies 'He encouraged the representatives to not focus on the exact amount of money.' (Christensen, 2007, 150)

Although a detailed treatment of the intricacies of the placement of infinitive markers in English and Norwegian extend well beyond the more modest focus of this article, our summary of these fundamental properties delivers two important points for our analysis moving forward: First, in both of the standard languages, (at least) three unique positions are required for the placement of $a$ (Wurmbrand, 2001, 2014; Christensen, 2007). Again, we conceptualize these positions to be the functional heads $v_{\text {INF }}$, T, and Fin as we have established in Figure 1. Although all three positions are possible in both languages, Situations/TPs have a more restricted distribution in Norwegian - especially with respect to ECM2-predicates. Second, as suggested independently by Christensen (2007) and Faarlund (2015), this state of affairs lends itself to an analysis via cyclic head-movement. 
A major difference between English and Norwegian that is highly relevant for our analysis, is the fact that Infinitival constructions can be licensed as objects of a preposition in Norwegian (cf. the discussion of til $a$ in (17) and (18)). Several common expression types in English infinitive syntax are ungrammatical in Norwegian unless there is also a preposition in front of the infinitive marker. On the other hand, such expressions with [PP $+\stackrel{a}{a}+\mathrm{INF}]$ are very common in all types of Norwegian, and (directly translated word-by-word) they are all ungrammatical in English. A substantial treatment of this (within a generative framework) is found in Aakervik (2006) - a detailed and theoretically robust masters' thesis with analyses of the syntax of Norwegian Infinitival clauses comparative to English, based on large amounts of corpus data. Examples (21a-d) render one example that demonstrate this difference in grammaticality. The comparison of (21c) with (21d) illustrates the impossibility in standard English for non-finite clauses to function as objects of the preposition til 'to', which is grammatical in Norwegian.
a. The student was rarely eager [to read].
[English].
b. ${ }^{\star}$ Studenten var sjelden villig [å lese].
[Bokmål]
c. Studenten var sjelden villig [til å lese].
[Bokmål].
d. ${ }^{*}$ The student was rarely eager [to to read]. [English]
(Aakervik, 2006, 2)

The impossibility in English for non-finite clauses to function as objects of prepositions, (contrary to Norwegian), also applies to similar constructions with other prepositions, as demonstrated by (22a-d) with for 'for' and om 'about', (both ungrammatical in Norwegian without the preposition):
a. Vi vil gjøre alt [for å bekjempe dem].
[Bokmål].
b. We will do everything we can $\left[\left({ }^{*}\right.\right.$ for $)$ to defeat them]. [English].
c. Ønsket [om å fåmindre trafikk og forurensning]. [Bokmål].
d. ${ }^{\star}$ The desire [( ${ }^{\star}$ about $)$ to have less traffic and pollution]. [English]
(Aakervik, 2006, 33-37)

In $\$ 4$ we will return to examples such as those in (21) and (22).

\subsection{Allomorphic variation of infinitive markers in dialectal Norwegian}

Since vernacular regional dialects of Norwegian played a major role in shaping AmNo grammar, a short primer on this dialectal variation is warranted. It is important to note that some degree of allomorphic variation exists here, with not all dialects consistently using the $\stackrel{a}{a}$-infinitive. For example, te is recognized as an alternate infinitive marker in some Norwegian dialects. (/te/ is the most common pronunciation of the preposition 'til'.) Aasen (1848) provided a description of the grammar of Norwegian dialects based on extensive national fieldwork and lists $\stackrel{a}{a}, t i l-a$, and te as infinitive markers. ${ }^{10}$ In Aasen (1853), consisting of text samples from all the different dialect areas, partly as a test-running for a new Norwegian written language, both $a$ and te are reported in many dialects throughout the country. ${ }^{11}$ 
Nesse (2003) claims that te as an infinitive marker first appeared in the Bergenregion in the Hansa era as a contact phenomenon, and then spread to other WestNorwegian dialects. This proposal is rejected in Faarlund (2003), showing examples with te from an earlier period of time and other parts of the country. Norsk Ordbok (n.d.), a dictionary of Norwegian dialects, mentions briefly in their entry on the preposition til that this can be "used directly in front of verbs in infinitive" (our translation). With respect to geographical areas, western Norwegian is mentioned as an area where "te is even often used as infinitive marker" (our translation). ${ }^{12}$

A search for te + infinitive in LIA Norwegian - Corpus of Older Dialect Recordings (Language Infrastructure Made Accessible, 2019) in Søfteland et al. (to appear), which was limited to Informants born between 1860 and 1920, delivers examples from all over the country, but with a clear majority from western dialects. Inspecting these data, there seem to be two consistent patterns that are noteworthy to mention. First, we observe many examples of te standing in for til å (preposition + infinitive marker) when compared with Bokmål. Second, primarily, but not exclusively, in West-Norwegian dialects we find the replacement of te for the expected allo-

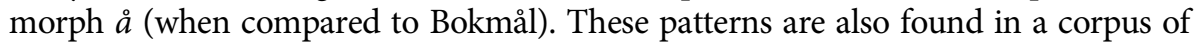
spoken Norwegian with more modern data (NDC; Nordic Dialect Corpus); see Huus (2018) for a more detailed study. Examples (22)-(25) show the usage of te as an infinitive marker within these patterns (from the mentioned LIA corpus); (23) from Lindås is an example of western Norwegian, and (24) (Seljord) and (25) (Fredrikstad) represent two different varieties of eastern Norwegian (the expected Bokmål infinitival marker is å for (24) and til å for (24) and (25)). ${ }^{13}$

$$
\begin{aligned}
& \text { me lærde no te lesa ætt måroværrs } \\
& \text { we learned now INF read a morning-verse } \\
& \text { 'We learned to read a morning verse.' }
\end{aligned}
$$

(lindaas-uib-0101)

(24) næi eg æ så klæin te sønnje eg nå at e kann kje no I am so bad INF sing I now that I can not 'I am so bad at singing now that I can't.' (lindaas-uib-0101)

(25) fikk nøkk ikke låv te fly ute åmm kvelln vi got probably not permission INF fly out at night.DEF we 'We probably weren't allowed to run around at night.' (fredrikstad-uio-0301)

Faarlund (2003) analyzes the dialectal infinitive marker te as a reanalysis of the frequent combination $t i l+\stackrel{a}{ }$ in Norwegian, considering also that the pronunciation of the preposition 'til' was reduced to /te/ long ago. ${ }^{14}$ According to Faarlund (2003), since nouns and adjectives in infinitival constructions could be followed (frequently) by either the combination til $\stackrel{a}{+}+V$, til $+V$, or $\stackrel{a}{a}+V$, the preposition til could be reanalyzed as an infinitive marker.

Historical documentation such as that of Aasen (1853) describes, as mentioned, both $\stackrel{a}{a}$ and te as infinitive markers, sometimes within the same text sample, from several different dialectal regions. A more thorough investigation of the distribution of these allomorphs may reveal finer-grained idiosyncrasies concerning this 
variation, ${ }^{15}$ however, our rationale for mentioning this is far more modest. Based on the descriptions provided by Aasen $(1848,1853)$ and the data from the LIA-corpus of older dialect data, it is quite likely that the usage of te as infinitive marker made its way across the Atlantic and existed in the substratum of linguistic input that shaped AmNo. Unfortunately it is impossible to know the extent of this influence, because (i) we do not know how widespread this feature was geographically and in frequency, and (ii) most of the CANS-informants have either a 'mixed' or 'uncertain' dialectal background (but see Hjelde (2012) and Johannessen \& Laake (2012) for a discussion of the status of eastern Norwegian in AmNo communities). Lastly, the near-homophony that exists between dialectal Norwegian te and English to is coincidental; however, it may be possible that this situation could potentially lead to an overextension of the te-infinitive marker in AmNo, which is a point we return to in $\$ 4$. Although we observe allomorphic variation in the realization of infinitive markers, especially in western Norwegian dialects, there appears to be no noticeable differences in the structural distributions of non-finite complements when different spoken language varieties are compared.

\section{Research questions and hypotheses}

Our review of the distribution of infinitive markers as an indication of non-finite complementation strategies available in English and Bokmål reveals that in both

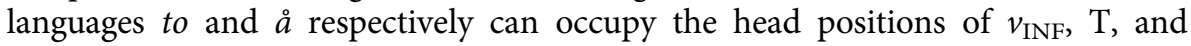
Fin. Norwegian exhibits a restricted use of Situations/TPs as non-finite complements (especially with respect to the licensing of ECM2-predicates). Although dialectal variants of Norwegian display some degree of allomorphic variation with respect to the realization of infinitive markers (e.g., $\stackrel{a}{a}$ vs. $t e$ ), the possible structural positions of these alternations remains the same. This state of affairs shows that cross-linguistic influence between English and (dialectal) Norwegian should essentially be a negligible factor in any deviations from what is observed in Bokmål. We acknowledge, in principle, that the extension of TPs as non-finite predicates in AmNo under the influence of English could be an instance of cross-linguistic influence (CLI; Jarvis \& Pavlenko (2008); Aboh (2015)).

The following research questions guide our analysis of the distribution of infinitive markers in AmNo:

- RQ1: Do we observe a reduction in the options that non-finite complements appear in in AmNo?

- RQ2: Is it possible, or prudent, to attribute any observed changes/deviations from a comparison with any baseline 'standard' as instances of attrition?

- RQ3: Do we observe any incipient patterns that diverge from both English and dialectal and 'standard' Norwegian? If so, how frequent are these forms and what might they tell us about the status of non-finite complementation in AmNo?

As we explicate in more detail in the subsequent section, there are instances in which AmNo significantly deviates from Bokmål, dialectal Norwegian, and even 
English in developing nuanced non-finite complementation strategies, and it is precisely these data that we turn our primary attention to in the forthcoming analysis. We explicate in our analysis in $\$ 5.1$ that, although the majority of AmNo-tokens display expected patterns found in Bokmål and dialectal Norwegian, the innovative structures that do not have a direct correspondence to forms in either English or homeland Norwegian receive a straightforward account if we interpret them as resulting from the overextension of grammatical principles already present in the heritage language grammar.

\section{Non-finite complementation in AmNo}

In this section we document and discuss instances of non-finite complementation in the free speech of AmNo-speakers. Here we illustrate this point with examples that are similar to Bokmål standard norms (\$4.1), regional Norwegian dialects (\$4.2), and also those that appear to match English (\$4.3). In addition to these 'matches', we explore nuanced non-finite complements which do not appear to neatly match any of these previously mentioned grammars ( $\$ 4.4 \& \$ 4.5)$. We will also comment on the frequency of these different types of non-finite complementation (mostly in $\$ 4.6$ ).

The source for the AmNo data analyzed in this paper is the Corpus of American Nordic Speech (CANS), housed at the University of Oslo's Text Laboratory (Johannessen, 2015). ${ }^{16}$ CANS presently consists of interviews and conversations with 205 AmNo-informants living in 45 locations in the USA and Canada. The data will be presented in its 'phonetic' transcription (i.e. phonetic with a regular alphabet, see corpus web page for details), but often with pauses and hesitations left out for clarity for the reader. ${ }^{17}$ In the written standard Bokmål the infinitive marker is $\stackrel{a}{\text {. In }}$ the written standard Nynorsk, based on rural Norwegian dialects, te can be seen occasionally by writers having this feature in their own dialect. As already mentioned, $a$ is the most frequent infinitive marker in modern Norwegian spoken language, and also used to be highly frequent earlier, even if te might have been at least as frequent some hundred years ago (cf. \$2.2). An important point is also that no homeland Norwegian dialects have only te in their repertoire, they always have $a$ to some extent (Strand, 2015; Huus, 2018).

There is a substantial amount of variation in the AmNo data. In total, $\stackrel{a}{a}$ as the infinitive marker is the most frequently produced form, but different pronunciations of $t i l$, mostly /te/, is quite frequent as well. We will look quite closely into the use of the whole te a before infinitives, since this is a frequent combination in both older an newer Norwegian, both spoken and written. As we have seen earlier, te $(\stackrel{a}{)})$ has several different functions in Norwegian, and te å could be analyzed both as two separate units (e.g. preposition + infinitive marker) or the whole chunk as the infinitive marker.

In the following we will describe the variation found in the corpus. Because of the lack of information of an adequate baseline (cf. \$2.2), we will compare all the AmNo examples with the written standard Bokmål. Admittedly, this is problematic, since Bokmål in itself cannot stand as baseline for the AmNo speakers included in CANS. However, to address this issue, we will compensate as much as we can by including all known dialectal variation in the discussion when relevant, and we will point out 
when the use of the infinitive marker could be considered (i) similar to written Bokmål, (ii) similar to homeland Norwegian dialects as far as we know, or (iii) divergent when compared with all or most varieties of Norwegian (to our knowledge). Note that we find innovative patterns for $\stackrel{a}{a}$ and $t e \stackrel{a}{a}$ both amongst speakers that can have te as an infinitive marker alone, and those who do not. Also note that in the majority of all examples with 'only $t e$ ' and in the majority of all examples with the whole te å heading an infinitival clause, there would be an English equivalent sentence with (only) the infinitive marker to.

\subsection{AmNo: Bokmål-like examples}

\subsubsection{Bokmål-like with å}

The majority of tokens with an infinitive preceded by (some kind of) infinitive marker in CANS, have $\stackrel{a}{a}$ as the infinitive marker in settings where Bokmål would also have å (i.e. definitely similar use); see (26)-(28) as examples. In each example here and in the following: The first line is the actual CANS-utterance cited from the corpus, presented in its phonetic transcription (as described above). The second line is a direct glossing to English, where $a$ is marked as INF and te as PRP (except when te is the infinitive marker alone), and the third line gives a translation in English, translated as directly as possible from the Norwegian original (expected Bokmål form for these examples: å).

$$
\begin{array}{llllllll}
\text { e synes de } & æ & \text { så } & \text { kosjli } & \text { a } & \text { prate nåssjk } \\
\text { I think it } & \text { is } & \text { so } & \text { cozy } & \text { INF } & \text { speak } & \text { Norwegian }
\end{array}
$$

'I think it's so nice to speak Norwegian.'

(CoonValley-17gm)

(27) e prøver å skrive nåRsk

I try INF write Norwegian

'I try to write Norwegian.' (Decorah-01gm)

(28) je har inngentinng å jøra hær i biin

I have nothing INF do here in town.DEF

'I have nothing to do here in town.' (Outlook-06gm)

The examples above reflect some of the most frequent construction types in the data, expletive constructions with postverbal AP (26), infinitival constructions licensing a pro subject (27), and control infinitive constructions with the raising of a quantifier from an infinitival relative clause (28). In all of these environments above, and in the majority of similar environments in CANS, we observe an $a$ infi-

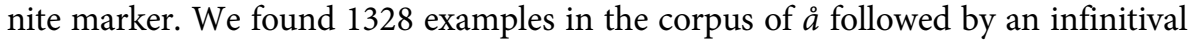
clause (without a preposition preceding it). ${ }^{18}$

Another related example found in the corpus data involve non-finite clauses headed by the adverbial åsså:

så $\mathrm{n}$ bynnte åsså rydde lann dær
so he began INF clear land there
'So he started to clear land there.'


In (29), the Bokmål counterpart would be $a$, however the use of åsså is also attested in colloquial homeland Norwegian (Faarlund et al., 1997, 994). We found 44 examples in CANS where åsså is clearly heading an infinitival clause (including a few tokens with a preceding te, cf. \$4.4.1).

\subsubsection{Bokmål-like with te å}

As mentioned previously, the preposition te is often followed by $\stackrel{a}{+}+$ infinitive, in Norwegian in general, in different types of non-finite environments. The AmNo examples in (30)-(34) are of this type, similar to written Bokmål and most varieties of the spoken language. In all these examples, til å would be the Bokmål counterpart. (Both /te/ and /ti/ are common pronunciations of the preposition til.)

(30) $\quad$ i $\quad$ e fø gammall ti å reise I am too old PRP INF travel 'I'm too old to go.' (Hatton-02gm)

(31) du hadde vel itte nåkk peeng ti å jiffte re før you had well not enough money PRP INF marry refl before 'You didn't have enough money to get married earlier, did you?' (CoonValley-07gk)

(32) ann sa re (.) att hu kåmm itte te å mekka re he said that (.) that she came not PRP INF make it 'He said that she wasn't going to make it.' (Westby-12gm)

(33) att o såg ut te å va nåkkså tjekk jennte that she looked out PRP INF be quite nice girl 'that she seemed to be a quite nice girl.' (CoonValley-06gm)

(34) viss du kann få hann te å snakka nårssk if you can get him PRP INF speak Norwegian 'If you could get him to speak Norwegian.'

(Saskatoon-01gk)

All these construction types are produced relatively frequently in both AmNo and homeland Norwegian. In (30) the infinitive construction with $a$ is a complement to a graded AP $+t i l$, and in (31) the infinitive construction with $a$ is a complement to a graded NP $+t i l$. Both could be counted as control infinitives. In (32) and (33) the regular verbal constructions komme til a ('will', 'going to') and se ut til å ('look like', 'seem'), license the infinitival clause headed by $\stackrel{a}{a}$, and can be classified as instances of raising. (34) is a causative construction, fătil a ('get', 'make'), where the subject of the infinitival clause is co-referential with the object of $f a$ ' 'get'. ${ }^{19}$

In addition to the many examples with til $\stackrel{a}{+}$ an infinitival clause, there is also a

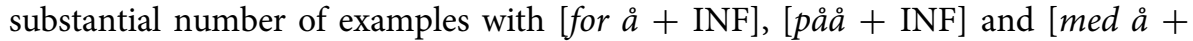
INF], and a few with av, etter, om, $i$ etc. (cf. \$2.1). In sum, we have found 389 examples in CANS with preposition followed by infinitive marker $a$ followed by an infinitival clause (from a total of 2120 examples with infinitive markers). 


\subsubsection{Split infinitives with $\stackrel{\circ}{a}$ and te $\stackrel{\circ}{ }$}

As for split infinitives in AmNo, the most frequent intervening adverbials in the corpus material are bare ('only') and messom/liksom ('like') (there are few examples with ikke 'not'; expected Bokmål infinitival form for (35) is å and for (36) til å):

(35) da barna v'R små prøvvde jæ å bare snakke enngelsk when children.DEF were small tried I INF only speak English jemme

home

'When my children were young, I tried to only speak English at home.' (Kalispell-02uk)

(36) demm a måtte funni væigere te å mæssåm førrstå enan they have must found ways PRP INF like understand each-other 'They've had to find ways to understand each other.' (CoonValley-17gm)

There are surprisingly very few examples of split infinitives in the CANS data; we have found 22 in total, including both $\stackrel{a}{a}$, te $\stackrel{a}{a}$ and $\stackrel{a}{s s a ̊, ~(n o n e ~ w i t h ~ o n l y ~ t e), ~ a l l ~ o f ~}$ which are common in Norwegian.

\subsection{AmNo: Norwegian dialect-like examples}

There is a substantial number examples in CANS, i.e. 337/2120, in which te appears as the lone infinitive marker. As mentioned, we find this feature in homeland Norwegian dialects as well. It is fairly unexplored in the syntactic research literature on Norwegian, but we know that it was probably relatively common by the time the initial generation of AmNo speakers emigrated to America (cf. \$2.2).

\subsubsection{Dialect-like with te where Bokmål licenses å}

Examples(37)-(39) are instances of AmNo non-finite complements that exhibit (only) te, in which Bokmål would license (only) å:

(37) åh re æ så gått te kåmma heim att oh it is so good INF come home again
'Oh, it's so good to come home again'
(Sunburg-11gk)

(38) hænn i læRRde te snakk enngels? where I learned INF speak English 'Where I learned how to speak English?' (CoonValley-17gm)

(39) remm læRde uss te snakke nåRsk they taught us INF speak Norwegian 'They taught us to speak Norwegian.' (Sunburg-03gm)

Here we see an expletive construction in (37) and control infinitive constructions in (38) and (39). Most of the relevant types of non-finite complements appear to be candidates for this optional marking. 
4.2.2 Dialect-like with te where Bokmål licenses til å

AmNo examples in which te appears as the lone infinitive marker corresponding to the combination til å in Bokmål (frequently pronounced as /te å/ or /ti å/ in spoken varieties) are shown in (40)-(44):

(40) menn va fø kallt ti gå på skuR'n but was too cold INF go to school.DEF 'But it was too cold to go to school.'

(Hatton-03gm)

(41) da fekk domm penng nåkk te tjøpe en gaR fø rømm sjøR then got they money enough INF buy a farm for them self 'Then they got enough money to buy a farm for themselves.' (Decorah-01gm)

(42) så bruka vi hesstan ti ri på so used we horses.DEF INF ride on 'Then we used the horses to ride on' (Sunburg-14gm)

(43) e trudde allder e kåmm te bi jifft I thought never I came INF become married 'I never thought I was going to get married.' (Sunburg-03gm)

(44) hu ser ut te væra mye innger she looks out INF be much younger 'She seems to be much younger.'

(Sunburg-17gm)

The use of the infinitive marker te in the examples above is also a dialect feature found in variants of Norwegian, and appears to be much more widespread than te, corresponding to only $\stackrel{a}{a}$ in the previously mentioned LIA-corpus and NDC (\$2.2). In the AmNo data from CANS these constitute approximately 50 percent more when compared with these aforementioned corpora. It is a notable challenge to determine with precision what the Bokmall-equivalent would be. As a result, it is not possible to provide exact numbers for comparison (see, e.g., $\$ 4.5$ and $\$ 4.6$ for further discussion). Clear restrictions in the distribution of te-infinitive complements in the AmNo data cannot be established. In (40) the infinitival clause is the complement of a graded AP, and in (41) the complement of a graded NP. In (42), the infinitival clause is the complement of a preposition. Examples (43) and (44) are regular verbal constructions like the ones seen in (32) and (33) in \$4.1.2).

\subsection{AmNo: English-like examples}

Up to this point in our survey of AmNo non-finite complements we have seen instances of te standing in for $\stackrel{a}{a}$ or $t i l \stackrel{a}{a}$ in Bokmål, or corresponding with te in dialectal varieties of Norwegian. In this section we take a closer look at examples that appear to resemble English-type non-finite complement clauses that exhibit the infinitive marker to. 


\subsubsection{English-like with Norwegian PP-counterpart}

In AmNo we also find several examples with (only) te whose equivalent translations in Bokmål require a preposition other than til to precede the infinitive marker; especially for $(\stackrel{\circ}{a})$, but also med $(\stackrel{\circ}{)})$ and etter $(\stackrel{\circ}{a})$ (cf. $\$ 2.1)$ :

(45) så må je læse te hølle mei opp på språke so must I read INF hold refl up on language.DEF 'So I must read to keep up my language.'

(Bokmål: for å)

(Westby-09gm)

(46) å jæ lenngte till treffe henne (Bokmål: etter å) and I long INF meet her

'And I long to meet her.'

(Saskatoon-14gk)

In the examples (45) and (46) we see that the corresponding English sentences only require the infinitive marker to. There is corpus evidence of dialectal Norwegian (LIA) where te stands in for the expected Bokmål marking for $\stackrel{a}{a}$, but these instances are quite rare, especially for other prepositions than for, such as (46). So, a plausible analysis is that the AmNo structures here are mirroring the English structures when it comes to the infinitive marker, syntactically and phonetically, with (only) te/til where English would have (only) to. These instances of non-finite TP predicates in AmNo could arguably be instances of CLI, which is to be expect to a certain degree in the syntax of bilinguals in light of the highly integrated nature of these grammar systems (Putnam et al., 2018).

\subsubsection{English-like with no Norwegian counterpart}

Next we turn to AmNo examples that appear to have no direct counterparts with neither Bokmål nor dialectal Norwegian, but rather are suggestive of calques of English non-finite complement clauses. There is variation concerning whether the infinitive marker is lexicalized as te (47)-(49) or as $\stackrel{a}{a}(50)$, but in all these examples the entire non-finite complement clause resembles an English-like adaptation:

(47) denn anndre levvde te være sju-å-åtti

the other lived INF be 87

'The other lived to be 87 (years old).'

Bokmål: 'Den andre levde til han ble 87.'/'Den andre ble 87 år gammel.'

(Saskatoon-14gk)

(48) dømm førtællja dæmm te sjnakke enng'lse they told them INF speak English

'They told them to speak English.'

Bokmål: 'De sa til dem at de måtte snakke engelsk.' (Coon Valley-12gm)

(49) menn ho visste va ti jørra

but she knew what INF do

'but she knew what to do.'

Bokmål: 'Men hun visste hva hun skulle gjøre.' (Saskatoon-01gk) 
$(50)$

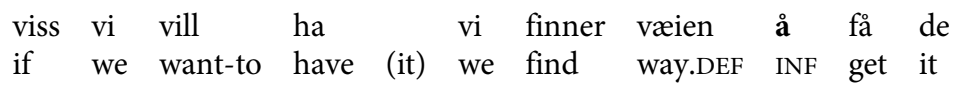
'I we want to have it, we find a way to get it.'

Bokmål: 'Hvis det er noe vi vil ha, finner vi en måte vi kan fådet på.'

(Chicago-01gk)

These examples appear to have changed their category according to the implicational scale discussed and outlined in Wurmbrand \& Lohninger (to appear); they license finite clausal complements in Bokmål and non-finite (English-like) ones in AmNo. In the CANS data we found around 30-40 examples of this type, some of them quite unclear because of (ambiguity between) code-switching or hesitations and repetitions. We leave a thorough examination of these examples for further research.

\subsubsection{Spost te $(\stackrel{\circ}{)})$}

Another structure found in AmNo that is also relevant for our treatment of nonfinite complementation is the one shown with the form spost te (or the like), approximating English supposed to:

(51) ru va spost te jera da you were spost INF do that

'You were supposed to do it.' (CoonValley-06gm)

(52) æ veit ittje ke re va spost te jørra

I know not what it was spost INF do

'I don't know what it was supposed to do.' (Madison-07gm)

(53) menn de e spås te renngne i mårrå sie rømm but it is spost INF rain to morrow say they

'But it's supposed to rain tomorrow, they say.' (CoonValley-06gm)

(54) vi e spåst tu prate

we are spost INF talk

'We're supposed to talk.' (Sunburg-12gk)

(55) å remm va spås te å sea hå slass fuggl etta va and they were spost PRP INF say what kind-of bird this was 'And they were supposed to say what kind of bird this was.' (Sunburg-07gm)

(56) e va spåost te å snakke nåRsk

I was spost PRP INF speak Norwegian

'I was supposed to speak Norwegian.'

(Hatton-02gm)

As shown in the glossing of the examples (51)-(56), the spost te $(\stackrel{\circ}{a})$ construction roughly equates with the English semi-modal supposed to. We found around 20 tokens in CANS exhibiting this construction, with some variation in pronunciation 
(e.g., sposst, spåst, spåost etc.), followed by te or $t u$, and a non-finite complement clause - sometimes accompanied with the infinitive marker $\stackrel{2}{a^{20}}$

Eide \& Hjelde (2012) provide a comprehensive treatment of this construction (and associated variants) in AmNo, primarily considering its semantic use (deontic and epistemic/evidential modality) and aspects of borrowing (matter replication and pattern replication). They conclude that $s p o(u) s t(t e)(\stackrel{a}{)})$ is used for both modalities, like supposed to in English, and that it is difficult to provide a definitive answer on the question of pattern replication, because the construction fits easily into other similar patterns in spoken English.

\subsection{AmNo: Forms with additional structure}

In this section we analyze CANS tokens in which the minimal requirements of Situations (TP) and/or Events $(v \mathrm{P})$ are met (see Table 4$)$, yet additional structure in the form of a preposition is added.

\subsection{1 te å when Bokmål has only å (innovative structures)}

Examples such as the following are not uncommon in the AmNo data, where what would be å in Bokmål (and only å or only te in spoken homeland Norwegian as far as we know), occurs as te $\stackrel{a}{a}$ in AmNo. Here, constructions with only an infinitive marker at some point have developed to a structural unit that can be analyzed as either [PP + infinitive marker] or a double infinitive marker: ${ }^{21}$

(57) åh hu tenngte de va galt te å ha tåll baRn and she thought it was wrong PRP INF have twelve children 'And she thought it was wrong to have 12 children.' (Saskatoon-14gk)

(58) nærr de va tonngt te å snakke nåssjk så snakke vi enngelsk when it was heavy PRP INF speak Norw. so spoke we English 'When it was hard to speak Norwegian, we spoke English instead.' (Saskatoon-07gk)

(59) de er fin tinng te å ha stor fameli

it is fine thing PRP INF have big family

'It's a good thing to have a big family.' (Saskatoon-14gk)

(60) de tæk kannsje omtrennt ein fæmm å førrti mennut

it takes maybe around a five and fourty minutes

tett på ein

close to one

time te å tjør opp dær

hour PRP INF drive up there

'It takes maybe about 45 minutes, close to one hour, to drive up there.' (Harmony-04gm)

(61) je har leRRt te å læsa no nåsk

I have learned PRP INF read some Norwegian

'I have learned to read some Norwegian.' $\quad$ (Fargo-02gm) 
(62) jei skulle like te å vere kann hennde i FaRgåo I should like PRP INF be may happen in Fargo 'I would like to be, maybe, in Fargo.'

(63) vi hadde så mannge slættning så vi hadde mannge te å besøke we had so many relative so we had many PRP INF visit 'We had many relatives, so we had many people to visit.' (Glasgow-01gm)

When compared with an approximate English translation, it is evident that the above examples (57)-(63) lack a direct correspondence, mainly due to the fact that English only has one infinitive marker (to) whereas AmNo could be said to have two in this case (te a). Examples (57)-(60) are different kinds of expletive constructions (i.e., IT-extrapositions with post-verbal APs and NPs), while (61) and (62) are regular control infinitives. Example (63) is an infinitival relative clause. We see these examples both among speakers who regularly use (only) te as an infinitive marker as well as those who always produce $a$ in front of infinitival clauses. This implies that te in (57)-(63) is likely not an infinitive marker, but a preposition - and te å not a double infinitive marker.

We also find occasional examples of the same kind of structure with the previously mentioned åsså (cf. \$4.1.1), in syntactic environments where Bokmål would have (only) å, some dialects might have (only) te and in the modern spoken language in general one could produce (only) åsså:

$\begin{array}{llllllll}\text { (64) så da binnt e te åsså mjøRRke } & \text { kuer } \\ \text { so then began I PRP INF } & \text { milk } & \text { cows }\end{array}$ 'So then I started to milk cows.' (Harmony-01gk)

In total, we found approximately 40 examples in CANS of the types shown in (57)-(63), where the constructions must be considered divergent from Bokmål, and as far as we know also compared to all or most varieties of spoken Norwegian.

\subsection{2 te å when Bokmål has for å (innovative structures)}

Thus far we have not encountered tokens in homeland Norwegian where the complex infinitive marker te å replaces frequent $[\mathrm{PP}+$ infinitive marker] combinations such as for $\stackrel{a}{a}$, med $\stackrel{\circ}{a}$, and etter $\stackrel{\circ}{a}$. Examples (65)-(68) below display this very pattern in AmNo (Bokmål infinitival marker: for å).

(65) hå råmm jikk ijønåm te å kåmm hær what they went through PRP INF come here 'What they went through to come here.'

(Westby-04gk)

(66) e tru ømm sennt åss te a ha morro

I think they sent us PRP INF have fun

'I think they sent us (there) to have fun.'

(CoonValley-03gm)

(67) såmm kåmm heR ti å bisøke em who came here PRP INF visit them 'who came here to visit them.' (Portland-02gk) 
(68) vi brukkte gå æi hall mil ti å slaide neåveR snøbanngkan we used go a half mile PRP INF slide down snow-banks.DEF 'We used to walk half a mile to slide down the snow banks.' (Hatton-02gm)

In our analysis, this 'overuse' of te å does not correspond to either homeland Norwegian or English. Both Bokmål and all (or most) spoken varieties of Norwegian retain the for å combination (with the possible occurrence of only te in some rural dialects, cf. \$4.3.1). English only marks these non-finite complement clauses with to, whereas AmNo here overextends the complex te a marker. In the CANS data we found approximately 25 examples like the ones shown in (65)-(68). This 'overuse' of te a adds to the data in $\$ 4.4 .1$ supporting an analysis that many AmNo speakers prefer te å over other possible markers in infinitival constructions, changing this in an analogical way.

An interesting observation supporting this claim, is that the CANS speakers appear to not overuse any of the other frequent prepositions initializing infinitival clauses in Norwegian (cf. \$2.1), such as for, på and med. In some utterances in CANS, the recorded informant seems to change his/her mind on the preposition (te-for) inside the sentence structure (Bokmål: for å):

(69) så enn æ gått te fårr å eta

so he is gone PRP for INF eat

'So he has gone to eat.' (Sunburg-01gm)

Examples such as (69) reflect the dynamic nature of the bilingual mind, and subsequently bilingual grammars and the representations that spawn from them. We return to the crucial role this fact plays in our analysis of non-finite complementation in AmNo in $\$ 5.1$.

\subsection{AmNo: Forms with less structure}

We conclude our review of nuanced AmNo non-finite complements by taking a closer look at structures that display reduced structure, i.e., those in which only the infinitive marker $\stackrel{a}{a}$ appears in AmNo tokens when Bokmål requires the combi-

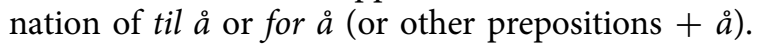

\subsection{1 'only å' when Bokmål has til å (innovative structures)}

Examples (70)-(76) display the 'reduction' of the expected te å combination to only å. Although some homeland Norwegian dialects may license only te in these contexts, to the best of our knowledge, the presence of $\stackrel{a}{ }$ without a preposition here is unexpected. ${ }^{22}$ We classify them as divergent from what is commonly found in Bokmål and dialectal Norwegian, but will nuance this discussion in general further down (Bokmål: til å).

(70) nårr je var stor nåkk å tjøre bannd'lvægen when I was big enough INF drive bundle-wagon 'When I was big enough to drive bundle wagon.'

(Decorah-02gm) 
(71) menn di err beddre enn me å snakke å fåssjtå nåssjk but they are better than me INF speak and understand Norw. 'But they are better than me to speak and understand Norwegian.'

(Spring Grove-09gm)

(72) e e kkji vannd å snakke me do då veit du I am not used INF speak with you then you know 'I'm not used to talk to you, you know.'

(Sunburg-10gm)

(73) mor var god å (.) lage klær for oss mother was good INF (.) making clothes for us 'My mother was good at making clothes for us.'

(Outlook-03gk)

(74) je har ikke anledning å snakke nåssjk så mye no mer I have not opportunity INF speak Norw. so much any more 'I don't have the opportunity to speak Norwegian that much anymore.'

(Chicago-01gk)

(75) tjemm å væ gla att e legg me i kvell come INF be happy that I lie refl in night 'I'm going to be happy when I go to bed tonight.' (CoonValley-04gm)

(76) så ho hadde (.) ville bere få hena (.) å vara i Oslo so she had (.) would only get her (.) INF be in Oslo 'So she had, only wanted to get her to stay in Oslo.' (Saskatoon-01gk)

In (70) and (71) the infinitival clauses are complements of graded APs ('big enough', 'better than'), in Bokmål with til in between (stor nok til å, bedre enn meg til å). Examples (72) and (73) are two common expressions in Norwegian (vore vant til å 'being used to' and vare god til à 'being good at') where the non-finite clauses here must be analyzed as being headed by APs since til/te is missing (compare e.g. with vore villig til $\stackrel{a}{\text { in }}(21)$ ). In (74) the infinitive clause is headed by a noun phrase (anledning 'opportunity'). Examples (75) and ((76)) are regular verbal constructions where the expected til/te is missing (komme (til) a 'is going to' and fänoen (til) å 'get someone to').

Compared with similar structures in English, one could make the case that in these instances AmNo licenses approximate English equivalents from a structural point of view (i.e., only one, simple infinitive marker), but lacks a direct counterpart in the morphosyntax (i.e., the $\stackrel{a}{a}$ infinitive marker is distinct from $t e$ ), which can be interpreted as instances of CLI. The examples listed above are most likely the result of $a$ being the default initializer of infinitival clauses. If compared with standard written Bokmål, around 70 examples in the CANS data could be categorized along with the ones shown in (70)-(76). When we shift this comparison to spoken Norwegian, however, this number becomes significantly lower. For example, around 15 of the cases are constructions with lyst (til) $a$ ('have the desire to') and lov (til) $a$ ('have the permission to'), where the regular Norwegian pronunciation would be without the preposition til. ${ }^{23}$ 
(77) sønn våres næi hann har inngen lisst å lære språk son ours no he has no desire INF learn language 'Our son, no, he doesn't want to learn the language.' (Fargo-04gm)

(78) me hadde ikkje løv $\quad$ å snakke nåssjk we had not permission INF speak Norwegian 'We were not allowed to speak Norwegian.' (Sunburg-10gm)

In addition, there are some tokens that are divergent from what is expected in Bokmål, but are attested in some regional dialects of Norwegian, typically constructions like flink (til) ̊̊a ('good at') as in (79) (Bokmål: til å):

(79) søssteR mi hu e meR flinngke å snakka sister my she is more good INF speak 'My sister is better at speaking.' (Saskatoon-03gk)

In (79), we have enough dialectal clues and biographical information to be able to judge the utterance as similar to dialectal Norwegian for this informant, but in many other cases this is hard to decide.

\subsection{2 'only å' when Bokmål has for å (innovative structures)}

Compared with the examples above, we also find tokens in CANS in which the (sole) infinitive marker $\stackrel{a}{a}$ is produced in place of forms with (other) prepositions in front (Bokmål: for å for all three examples below, and optionally for/av å for $(82))$.

$\begin{array}{llllllll}\text { (80) ja } & \text { bi } & \text { ness'n } & \text { redd } & \text { a } & \text { tjøre } & \text { på } & \text { denn } \\ \text { yes } & \text { become } & \text { almost } & \text { scared } & \text { INF } & \text { drive } & \text { on } & \text { it }\end{array}$ 'Yes, you almost get scared to drive on it.'

(Harmony-03gm)

(81) je va gla å hør de I was glad INF hear it 'I was happy to hear it.' ～(Webster-01gm)

(82) hunn spurte mæi åmm jæi hadde indresse å jåbbe me baRn she asked me if I had interest INF work with children 'She asked me if I was interested in working with children.' (Minneapolis-01uk)

Examples (80) and (81) are headed by APs, while (82) is headed by an NP. These again have English-like structure, e.g. [AP + infinitive marker + infinitive], and not the Norwegian-like structure $[\mathrm{AP}+\mathrm{PP}+$ infinitive marker + infinitive] - but the infinitive marker is the typical Norwegian one $(\stackrel{a}{a})$. (Examples such as $(80)-(82)$ are counted together with examples like (70)-(76) in the following quantitative analyses.) 
Table 2. Examples in CANS exhibiting an infinitive marker

\begin{tabular}{lc}
\hline only $a+I N F$ & 1328 \\
\hline prep $+a+I N F$ & 389 \\
\hline only te + INF & 337 \\
\hline$a ̊ s s a ̊+I N F$ & 44 \\
\hline split infinitives & 22 \\
\hline Total & $\mathbf{2 1 2 0}$ \\
\hline
\end{tabular}

\subsection{Summary of AmNo data}

Similar to Bokmål (\$2.1) and dialectal Norwegian (\$2.2), AmNo also appears to use three different complementation strategies. As we discuss below in $\$ 5$, these three strategies correspond directly with particular domains in syntactic structure (i.e., Propositions (CP), Situations (TP), and Events $(v \mathrm{P})$ ). The variation observed in the various infinitive markers is not exclusively allomorphic (except in the instances of lone $\stackrel{a}{a}-t e$ alternation) and reflect alternations in syntactic structure. Table 2 provides an overview of the distribution of infinitive markers and their accompanying non-finite complements analyzed in this study.

Most of the examples with [ $\stackrel{a}{a}+\mathrm{INF}]$ are similar to Bokmål and to most or all Norwegian dialects, but as we have seen in $\$ 4.5$, the number 1328 also includes a handful of examples with less structure than expected when both Bokmål and known varieties of Norwegian dialects are taken into account. The category [PP $+\stackrel{a}{a}+\mathrm{INF}]$ includes both til (the most frequent attested preposition) and other prepositions. The majority of the these examples are clearly similar to what is found in Bokmål, but there is a substantial number of [te $+\stackrel{a}{ }+\mathrm{INF}]$ examples that must be said to have more structure than expected when compared to both Bokmål and varieties of spoken Norwegian as far as we know; that is, AmNo-speakers seem to

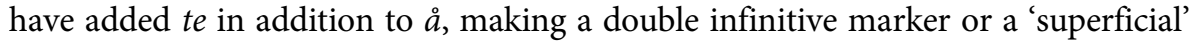
preposition + infinitive marker. An interesting observation made in $\$ 4.4$ is that AmNo speakers do not seem to do this with prepositions other than te 'til'.

The examples with [(only) te + INF] are 'divergent' when compared to Bokmål (standard written form til), but they show some degree of similarities to dialectal variants due to the fact that this feature appears to have been relatively widespread in older Norwegian spoken language from the main emigration period (cf. \$2.2). We do not have enough exact knowledge about the AmNo-speakers' dialectal background to know for sure if their use of te as an infinitive marker is a heritage feature or if it is primarily an influence from (the resemblance with) English $t o .{ }^{24}$ The structure [åsså + INF] can be found in spoken varieties of Norwegian to some extent (cf. $\$ 4.1 .1$ ). The type of split infinitive examples listed in $\$ 4.1 .3$ are all attested in homeland Norwegian, but there are still two interesting observations comparatively: i) We have not found any split infinitives with the infinitive marker $t e$, and ii) Split infinitives appear to be much less frequent in AmNo than in homeland Norwegian, which might be due to the fact that some of the earliest attestations of split infinitive in Bokmål and Norwegian dialects are traced back to the 1880s - after the generation of AmNo-speakers had immigrated to the US (Faarlund, 2007, 72). ${ }^{25}$ 
Table 3. CANS-examples with no direct English or Norwegian equivalent compared with expected Bokmål and/or dialectal forms

\begin{tabular}{lccc}
\hline & AmNo examples & Bokmål + spoken dialects & total \\
\hline Additional structure & te $\stackrel{a}{a}$ & a & ca. 40 \\
\hline Less structure & $a$ & te & ca. 50 \\
\hline
\end{tabular}

Some of the examples we have categorized as divergent have direct counterparts in English, either for the infinitive marker only (cf. \$4.3.1), or for the whole syntactic structure (cf. \$4.3.2), but a substantial number of examples are structurally different from both homeland Norwegian and English. Although the structural similarities found in the majority of examples reviewed in $\$ 4.4$ and $\$ 4.5$ lend themselves to a rather straightforward analysis, the situation is markedly more difficult when analyzing those exhibiting 'less structure'. The primary challenge we face is determining to what extent dialect variation may be at play in these forms. ${ }^{26}$ In summary, based on the most salient representative examples, we arrive at the following distribution in Table $3::^{27}$

The degree of variation in the structure of non-finite complements and their infinitive markers underscores three important points which we will touch upon in more detail in our analysis in the following section: First, there does not appear to be a discernible pattern in the AmNo data elicited from CANS in which certain types of infinitival constructions strongly prefer a particular structure in non-finite complementation. This also holds to a large extent at the level of the individual speaker. Second, the production of these various forms is a hallmark example of the dynamic and integrated nature of bilingual grammars (Putnam et al., 2018; López, 2020). Finally, in spite of this variation, there is a noticeable trend in the innovative, non-English and non-Norwegian like structures that show the tendency to add additional syntactic structure (in the form of a preposition) to AmNo nonfinite complement clauses $(\$ 4.4)$. In contrast, there are also instances in the innovative utterances where we see less structure than expected (i.e., when only a bare infinitive marker å occurs; see $\$ 4.5$ ) - a group of examples that are more difficult to analyze (ambiguous similar vs. divergent), but need to be accounted for nonetheless. In the remainder of this paper we turn our attention to providing an analysis of underlying innovative non-finite complements that do not have an immediate equivalent in either English or Norwegian (e.g., $\$ 4.4 \& \$ 4.5$ ) and the impact that these data and our analysis have on wider claims about the nature of heritage language syntax.

\section{Complementation of non-finite clauses: Core concepts}

Complementation involves the syntactic and semantic integration of (at least) two clause-level structures (also referred to as restructuring and clause-union). Achieving a better understanding of the semantic function of the embedded clause (Givón, 1980) and its syntactic configuration (Wurmbrand, 2001, 2014;Wurmbrand \& Lohninger, to appear; Wurmbrand \& Christopoulos, 2020) is the core mission of 
this domain of research. Here we provide a condensed overview of the key factors involved in complementation, based primarily on the summaries provided by Wurmbrand \& Christopoulos (2020) and Wurmbrand \& Lohninger (to appear).

With regard to syntactic structure, Wurmbrand \& Lohninger (to appear) claim that complement clauses have a tripartite distribution. Adopting the terminology of Ramchand \& Svenonius (2014), these domains are referred to as Propositions, Situations, and Events, which correspond with the syntactic projections CP (Propositions), TP (Situations), and $v \mathrm{P}$ (Events). The core properties of these clausal domains are summarized below in Table $4 .^{28}$

Propositions (CP) involve speech and epistemic contexts, Situations (TP/AspP) emotive and irrealis contexts, and Events $(\nu \mathrm{P})$ include implicative contexts. In their expansive overview on the general properties of complementation, Wurmbrand \& Lohninger (to appear) highlight a 3-way distinction of complementation subtypes: (1) Independence, (2) Transparency, and (3) Integration. Independence refers to presence - or the interpretation of - an independent subject or tense in the complement clause, whereas Transparency indicates that the embedded clause is available for certain operations or dependencies across its boundary. Finally, the notion of Integration indicates the degree to which the embedded predicate is incorporated, or fused, into the matrix predicate. As indicated in Table 4, Propositions (CP) are classified as the 'most complex' (i.e., most independent, least transparent, least integrated) of the three domains, with Events $(v \mathrm{P})$ being the 'least complex' (i.e., least independent, most transparent, most integrated); Situations (TP) lie somewhere in between.

An essential component of any formal analysis of complementation must afford some degree of syntax-semantics 'mismatches', i.e., instances where the syntactic structure in which a particular semantic interpretation is 'larger' than its semantics requires. This is the crux of our analysis of innovative non-finite clauses that we observe in the AmNo data investigated in this paper; namely, that either (i) CPsyntactic structures (indicated by the presence of a preposition) are applied to Situations (TP), or (ii) that reduced non-finite structures are only Events $(\nu \mathrm{P})$ in order to prevent 'naked' TP-structures from appearing.

\subsection{Avoiding naked non-finite TP-complements}

The variation observed in non-finite complement clauses in AmNo is a reflection of the dynamic nature of the bilingual mind, and subsequently bilingual grammar (Putnam et al., 2018; Hartsuiker et al., 2016). Any attempt to capture more general principles of the syntax of these systems must come to terms with the fact that multiple potential representations in bilingual syntax are the result of active competition of two systems that occupy the same cognitive space (Amaral \& Roeper, 2014; López, 2020). The AmNo data reviewed in $\$ 4$ confirm that although the majority of these tokens strongly resemble Bokmål and/or dialectal Norwegian, there exists a significant number of tokens that have been influenced by English ( $\$ 4.3)$ and another category of examples that do not strongly resemble either Norwegian or English ( $\$ 4.4$ and $\$ 4.5$ ). This final category of AmNo non-finite complement clauses, i.e., forms that do not have a direct correlate with either English or Norwegian, will be the focus of our theoretical analysis. ${ }^{29}$ 
Table 4. Tripartite clausal architecture of complements

\begin{tabular}{clll}
\hline & Proposition & Situation & Event \\
\hline $\begin{array}{c}\text { Syntactic clausal } \\
\text { domains }\end{array}$ & $\mathrm{CP}$ & $\mathrm{TP}$ & $v \mathrm{P}$ \\
\hline $\begin{array}{c}\text { Minimally required } \\
\text { functions }\end{array}$ & $\begin{array}{c}\text { Operator TMA domain Theta } \\
\text { domain }\end{array}$ & $\begin{array}{c}\text { TMA domain Theta } \\
\text { domain }\end{array}$ & Theta domain \\
\hline Complexity & most complex & intermediate & least complex \\
\hline
\end{tabular}

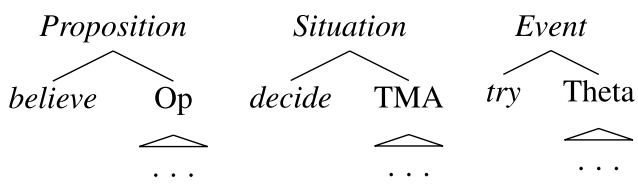

Figure 2. Minimal licensing requirements.

As a starting point for our analysis of the innovative non-finite complement clauses in AmNo found in CANS, consider the minimal syntactic licensing requirements of complementation found in Figure 2 taken from Wurmbrand \& Lohninger (to appear).

The minimal semantic requirements for complement clauses is one of an inheritance hierarchy (see Table 4$)$. The minimal licensing requirement for Events $(v \mathrm{P})$ are thematic requirements, while the minimal requirements for Situations (TP) include both thematic and TMA-requirements, and the minimal requirements for Propositions (CP) includes all three (Op(erator), TMA, Theta). Interpreting the licensing requirements of complement clauses according to these criteria also allows cross-linguistic variation concerning the amount of additional syntactic structure languages can project in complement clauses. Perhaps of equal importance is the fact that interpreting complementation as a syntax-semantics interface phenomenon - rather than a purely syntactic one licensed exclusively by categorial features - somewhat weakens the claim that complementation is an element of 'core syntax'. In the analysis we develop here, we adopt the stance that non-finite complementation is a combination of syntactic and semantic requirements: the predicate in the matrix (i.e., licensing) clause has certain (matching) requirements that must be compatible with those found in the candidate complement clause, along the lines of those outlined above. One of those licensing conditions responsible for ensuring compatibility between the matrix and complement clauses is a categorial feature (i.e., $v, \mathrm{~T}, \mathrm{C}$, or $\mathrm{P}$ (Wurmbrand, 2014)). ${ }^{30}$

We are now equipped to provide a working analysis for the innovative AmNo non-finite complements introduced in $\$ 4.4$ and $\$ 4.5$. First, we turn our attention to the instances where we find the addition of structure - in the form of a preposition - that cover up Events $(v \mathrm{P})$ and Situations (TP). To illustrate this, we repeat examples (57) and (59), now as (83) and (84) (Bokmål: å). 
(83) $\begin{array}{llllllllll}\text { hu tenngte } & \text { de } & \text { va } & \text { galt } & \text { te } & \text { a } & \text { ha } & \text { tåll } & \text { baRn } \\ \text { she thought } & \text { it } & \text { was } & \text { wrong } & \text { PRP } & \text { INF } & \text { have } & \text { twelve } & \text { children }\end{array}$ 'She thought it was wrong to have 12 children.'

(Saskatoon-14gk)

(84) de er fin tinng te å ha stor fameli it is fine thing PRP INF have big family 'It's a good thing to have a big family.'

(Saskatoon-14gk)

In both (83) and (84) we observe the addition of the te element which precedes the

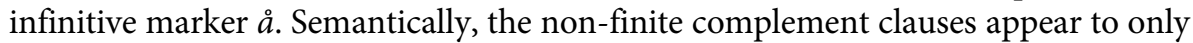
license thematic requirements, hence their minimal licensing domain would be $v \mathrm{P}$. This is held to be the case due to the lack of any propositional and/or situational semantics in these non-finite predicates. The appearance of te is an instance of the overextension of two elements of Norwegian syntax: First, recall that homeland Norwegian licenses ECM2-predicates only in restricted contexts (as opposed to English). Second, unlike English, a common feature of Norwegian is the appearance of prepositions at the edge of complement clauses. This HYPEREXTENSION leads to grammatical structures that avoid the appearance of being perceived as 'English', even if they are not licensed in the baseline grammar of comparison (here, Bokmål and all or most varieties of spoken Norwegian).

We advance the proposal that the preposition te resides in a higher PP-projection at the edge of the left periphery of the complement clause. ${ }^{31}$ Our motivation for this claim is twofold: First, placing the preposition te at the left edge of the periphery avoids the unwanted (morpho)syntactic homophony of having either of these markers appear in $\mathrm{T}$ (for reasons outlined in the paragraph above). ${ }^{32}$ Second, it mimics the L1, albeit via the overapplication of structures found in the baseline norm. These non-finite complement clauses that contain this additional syntactic structure are the result of Feature Reassembly (Putnam et al., 2019), according to which the feature requirements of the heritage grammar has been altered, either during the acquisition process or by means of additional developments throughout the course of the lifespan. Within this framework, the matrix predicate would possess a feature, whose value requires the appearance of te, therefore in these structures, the matrix predicate possessed an unvalued categorical $\mathrm{P}$-feature $[u \mathrm{P}]$, as illustrated in (85).

(85) Feature Reassembly for additional structure: $[\mathrm{CP} \mathrm{V}[u \mathrm{P}] \ldots[\mathrm{PP} t e[\mathrm{P}][\mathrm{CP} \varnothing[\mathrm{TP} \varnothing[v \mathrm{P}$ å $\ldots .]]]]$.

The tendency to make use of additional syntactic structure is a common trait found in heritage language syntax, which Polinsky (2018) refers to as structural salience. As a matter of fact, one need not look beyond heritage Germanic to find other languages that have also developed similar syntactic structures in licensing non-finite complement clauses. 
(86) Ich bin verschtaunt fer dich sehne do.

I am astonished INF you see here 'I am astonished to see you here.' [Pennsylvania German]

(Börjars \& Burridge, 2011, 393)

(87) Wij arbeira upm laand taum da arme luur helpen.

We work on.the land INF the poor people help

'We work on the land to help the poor people.' [Brazilian Pomeranian]

(Postma, 2018, 132)

Both Pennsylvania German (86) and Brazilian Pomeranian (87) exhibit structures similar to the overextended non-finite complements found in AmNo. Historically, Pennsylvania German had an infinitive marker $z u / z e$ that was lost in the course of its development. The prepositional element in the Pennsylvania German purposive - a construction consisting of the preposition fer 'for' and the infinitive marker $z u / z e$ - now stands as the marker of non-finite complementation (see Louden $(1988,1997))$ for additional information). In similar fashion, the infinitive marker taum in Brazilian Pomeranian is derived historically from the morphological blend of the infinitive marker tau + the dative definite article dem, which has been reanalyzed as a complex complementizer (tau $+\ddot{u} m$ 'for.to'). The key difference between the two being that in Pennsylvania German, the infinitive marker $z u / z e$ has been lost, whereas in Brazilian Pomeranian the infinitive marker is incorporated into the complementizer. What is relevant for the current discussion is that both varieties have opted to mark their non-finite complements with additional material -in the form of complementizers/prepositions - at the left periphery (i.e., likely realized as a $\mathrm{P}$, but potentially as a C) of the non-finite complement clause. ${ }^{33}$

Some notion of overextension is also responsible for the innovative non-finite complements in AmNo that show a reduction of structure, i.e., the elimination of the preposition in favor of a 'bare' $\stackrel{a}{a}$ infinitive marker. Examples (70) and (71) are repeated below as (88) and (89) (Bokmål: til å).

(88) nårr je var stor nåkk å tjøre bannd'lvægen when I was big enough INF drive bundle-wagon 'When I was big enough to drive bundle wagon.' (Decorah-02gm)

(89) menn di err beddre enn me å snakke å fåssjtå nåssjk but they are better than me INF speak and understand Norw. 'But they are better than me to speak and understand Norwegian.'

(SpringGrove-09gm)

In both (88) and (89) the preposition til/te, which is expected here in both Bokmål and dialectal Norwegian, does not appear, thus suggesting at a bare minimum that the non-finite complements here are 'smaller' than CP. The preference for marking

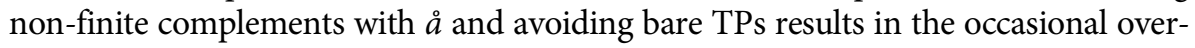
extension of $v \mathrm{P}$ complements, likely motivated at least to some degree by CLI with English. Example (88) represents a comparative AP that licenses a non-finite 
complement, and example (89) translates to a gerund construction in English, which have arguably less structure than a full $v \mathrm{P}$ (Fukuda, 2012). Again, it is difficult to identify a set pattern of matrix clauses that prefer one complementation strategy over others through the AmNo data analyzed here. For example, (88) and (89) have non-finite complements licensed by graded adjectives. Analogous to our treatment of the categorical feature responsible for generating additional structure, we propose that this instance of overextension resulting in the embedded clause only being an Event $(v \mathrm{P})$ is motivated by an unvalued $[u v]$ feature;

(90) Feature Reassembly for reduced structure:

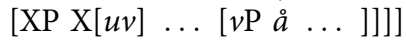

Taken together, the underlying structure proposed for these innovations of nonfinite complementation in AmNo avoids the licensing of TP-complements. This optionality casts doubt on analyses that attempt to license complementation on purely syntactic grounds (see Wurmbrand \& Lohninger (to appear) for empirical data and conceptual arguments). As a result, complementation is best understood as a syntax-semantics interface issue, with syntactic categorical features playing a somewhat reduced role in capturing this optionality.

In addition to the majority of examples of non-finite complementation that mimic Bokmål and dialectal Norwegian, we find instances of English-influence, and innovative structures that do not (immediately) resemble either source grammar in this dyad. These nuanced structures find their origin in the L1 heritage Norwegian grammar of these remaining AmNo-speakers, expressed here as an overextension of the tendency to avoid bare TP-complements and for their output forms to appear to be 'more Norwegian' and 'less English', at least in the sense of whether the prepositional complement is realized. These patterns are not unique to AmNo and are attested in other varieties of heritage Germanic languages (e.g., Pennsylvania German and Brazilian Pomeranian). AmNo is thus not undergoing any sort of prima facie systemic collapse (Bousquette \& Putnam, 2020); rather, what we are observing are instances of grammatical growth and nuance rather than the shrinking of this grammatical system (Putnam, 2020).

\section{Conclusion}

American Norwegian, a moribund heritage language, has been shown here to entertain the possibility of multiple syntactic representations in the speakers' production of non-finite complement clauses. Although the recorded tokens in CANS confirm that in the majority of instances AmNo speakers produce forms similar to those found in Norwegian (both standard and vernacular varieties), there are a number of deviations that show heavy English influence, and in some cases, innovative structures that resemble neither source grammar in this dyad. In this paper we made our case for analyzing these syntactic nuances as instances of overextension (Kupisch, 2014; Rinke \& Flores, 2014; Rinke et al., 2018; Putnam \& Hoffman, 2021) as a means to facilitate STRUCTURAL SALIENCE (Polinsky, 2018) in the syntactic representations of the heritage grammar. Innovative non-finite complement strategies in AmNo result in an increase in $v \mathrm{P}$ and (structural) $\mathrm{CP}$-complements in order 
to avoid bare TP-complements. Returning to our research questions posed in $\$ 3$, in connection with RQ1, rather than observing a reduction in the inventory of structural options for non-finite complements in AmNo, we actually observe an expansion. Turning to RQ3, the very existence of these incipient patterns of overextension to avoid bare non-finite TP-complements attests to the creative nature of human grammar, even within the constraints of plausible deficits in quality and quantity of input during the acquisition process and increasingly limited opportunities to use the heritage language in the decades that followed.

These findings and the motivation for the production of these divergent representations of non-finite complement clauses in AmNo raise important questions that lie at the heart of current debates in heritage language syntax. A key question here is whether the patterns of non-finite complementation are more characteristic of attrition or some degree of divergent attainment (related to RQ2). The high degree of intra-speaker variation and the fact that the predominant pattern found in the AmNo data resemble homeland Norwegian-like complementation strategies suggest that we are observing behavior more typical of attrition rather than divergent attainment (Polinsky, 2018, 28) (see Kinn (2020) for similar arguments for predicate nominals in AmNo). Although we are not likely dealing with divergent attainment in this domain (yet), there are two reasons why these findings are significant for current theorizing concerning the syntax of heritage grammars: First, the AmNo data do not reveal a collective pattern of significant language loss with respect to non-finite complementation options (or in other domains of grammar). This state of affairs is yet another instance of moribund grammars maintaining a significant degree of grammatical complexity in addition to the creation of innovative representations that do not directly correlate with either of the source grammars (Bousquette \& Putnam, 2020), nor does it appear to be in line with some sort of strategy to achieve representational economy (Scontras et al., 2018). Here we observe further language development (Putnam, 2020) in addition to the strong trend of the maintenance of L1 representations. Second, this variation in complementation strategies observed in AmNo could be classified as a microparameter in the sense of Roberts (2019). Taking this claim at face value, this variation does not compromise the general invulnerability of the core syntax of heritage grammars (Polinsky, 2018; Lohndal, 2021). The AmNo data analyzed in this paper reveals more about the complex syntax-semantics interface principles - as well as their influence on the realization of infinitive markers and prepositions - that operationalize complementation.

The inclusion of heritage language grammars into the formal study of the development of syntax stands to make lasting contributions to our more general understanding of human grammars (Lohndal et al., 2019). Polinsky and Scontras' (2020) call for theoretical approaches to heritage grammars to strive for a level of explanatory adequacy and predictability of developmental trajectories are essential goals for the development of formal treatments of these grammars. The results of this study, like others before it, emphasize the importance of coming to terms with the emergence of innovative and divergent representations that may not share a direct correlate with either source grammar in a particular dyad. Even if these nuanced structures are not the dominant output form, their existence speaks to the dynamic and integrated nature of the bilingual mind. The findings in this study suggest once 
again that heritage language syntax at its core is remarkably sturdy, arguably invulnerable, supporting long-standing assumptions about the nature of the cognitive architecture underlying the faculty of language (Lightfoot, 2020). More specific to heritage language grammars, these findings demonstrate that syntactic innovation - even in moribund varieties with a limited number of remaining speakers - is an indication of the retention of a robust and highly functional syntax (Bousquette \& Putnam, 2020).

Acknowledgements. We dedicate this paper to the memory of our colleague and friend Janne Bondi Johannessen. We thank Arnstein Hjelde for collaboration on an earlier stage of this project and the participants of WILA 11 for their excellent questions and comments. We owe a debt of gratitude to 3 anonymous reviewers, Tor Åfarli, Yvonne van Baal, Terje Lohndal, and David Natvig for comments and suggestions which significantly strengthened this paper. Lastly, we thank Robert Klosinski for proofreading the final version of this manuscript. Any remaining errors are solely the fault of the authors.

\section{Notes}

1 See Hjelde (2012) for a discussion of the extent to which it could be classified as a koiné.

2 As a point of reference, the majority of AmNo-speakers in the CANS-corpus are from the Upper Midwest, but there are a few disparate speakers from areas such as Saskatchewan and further West into Montana and Washington.

3 An anonymous reviewer raises a relevant point concerning the state of proficiency of the AmNo speakers, whose speech is recorded and analyzed in the CANS-corpus. Although it can be generally assumed that the vast majority of these speakers are of the final or penultimate generation of proficient speakers, we can only speak of their proficiency in general qualitative (as opposed to specific quantitative) terms.

4 For more on the syntax of tenseless clauses, see Stowell $(1982,2007,2012)$ and Wiklund (2007). As a matter of fact, Wurmbrand $(2001,2014)$ goes so far as to suggest that there is no evidence that to is a tense marker.

5 For a summary of the key distinctions among control, raising, and ECM-predicates, see Davies \& Dubinsky (2008).

6 Abraham's (2004) claim that infinitival markers are full phrases (XPs) does not hold up, since they cannot be further modified (which is a common property of XPs).

7 An attribute which distinguishes English from Norwegian infinitive markers is the observation that to can function as a tenseless auxiliary (or modal) as a system immediately adjacent to VP (Pullum, 1982; Levine, 2012; Arnold \& Borsley, 2010; Ojea, 2008). To date, we have not found examples of $a$ in AmNo that reflect this usage, so we will not discuss this distinction further in this paper.

8 An anonymous reviewer points out that it is difficult to establish whether or not predicates such as believe and expect have exact equivalents in Bokmål, let alone in AmNo.

9 A proper analysis of the placement of negation in Norwegian is admittedly difficult. Leaving aside the finer details of his analysis, Lindstad (2007) asserts that negation occupies two primary positions in Norwegian: (i) immediately dominating $v \mathrm{P}$ and (ii) immediately dominating TP.

10 See Mørck (2019) for an extensive diachronic analysis of the infinitive marker in earlier stages of Norwegian.

11 te is also found as an infinitive marker in some Swedish dialects, see Hagren (2008) and Kalm (2016).

12 Original quote: "til III. prep. ( . . . 9. nytta fyre verb i inf., t.d. hava nook - å gjera, d.s.s. hava noko ågjera (H); i dette høvet vert "til å" ofte avstytt til "til" (el. "te"), soleis: hava mykje - gjera; (...)" "Vest i landet vert "te" jamvel ofte bruka til infinitivmerke" (University of Bergen \& of Norway, n.d.)

13 As a point of reference, we have not encountered any examples of te te + INF (preposition 'te' + infinitive marker 'te') in homeland or American Norwegian. Note that the combination to to + INF in English, cf. comparative comments in $\$ 2.1$, also does not exist.

14 The pronunciation of 'til' as /til/ in some urban dialects and in received pronunciation of Bokmål is likely due historically to Danish influence. 
15 For example, in one of the background documents from Norsk Ordbok, the so-called Grunn-manuskriptet there is a brief mention on 'active infinitive' with te and 'passive infinitive' with å following a few examples, but no explanation. (Original quote: "Han a gó te (å) kjenne folk" (aktiv inf.); men: "doe a lett å sjå, han ce lett å kjenne, der va kje hús å fă" (passiv inf.)" (University of Bergen \& of Norway, n.d.)) From a synchronic perspective, an incipient analysis of the distribution of $a$ and te in a modern south-western Norwegian dialect by Strand (2015) shows some trends, for instance that te is most likely to appear in tough-constructions and expletive constructions with AP + INF, and least likely to appear in (subject-)raising constructions.

$16 \mathrm{http}: / /$ tekstlab.uio.no/norskiamerika/english/corpus.html

17 The CANS-corpus is open access with recordings linked to their transcription.

18 This number also includes a few examples with $a$ that would have no infinitive marker in Bokmål, but could have it in some dialects, such as Jeg kan ålese norsk ('I can to read Norwegian'), cf. (Faarlund et al., $1997,471)$. We have not included examples where $a ̊$ is followed by a participle, such as Det skulle voert moro a gått til Norge en dag ('It would have been fun to travel(ed) to Norway some day'), that is also found in many homeland Norwegian varieties (see Eide (2011), Sandøy (1991) and Aagaard (2016) for in-depth analyses).

19 Recall that in most of these cases with te å, there is a direct English counterpart with infinitive marker to, as shown in the translations, but the direct glossing would be to to, e.g. too old to to go, where the first to corresponds to the English preposition to, and the second to to the English infinitive marker to (cf. 2.1). 20 The variation between $t e$ or $t e+a$ could to some extent stem from different choices in the transcription (and not actual linguistic differences), but also from (corresponding) different analogical analyses by the language users: Does the - $t$ - belong to the verb or is it (part of) the infinitive marker? Especially in language maintenance environments where both infinitive markers ( $a$ and $t e$ ) can be heard, there is clearly room for reanalysis and/or variation among the speakers of AmNo.

21 We could add that something similar have happened the last decades in (urban) spoken Norwegian in a regular verbal construction: tenkt $\stackrel{a}{+}$ INF ('planned to + INF') is pronounced (and written) as tenkt til $\stackrel{a}{+}$ INF by an apparently increasing number of people. (Also see Lødrup (2002) for detailed discussions of this example and other comparable cases from Bokmål.) The development for tenkt (til) å might be comparable

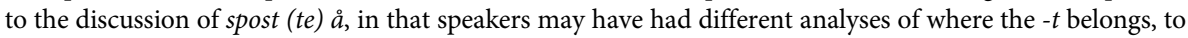
the verb or to a complex infinitive marker. This ambiguity is also apparent in many transcriptions in the speech corpora of [word ending in $-t+(t e ?)+\stackrel{a}{\text { ] }}$; it is clearly hard to decide if $t e / t i l$ is spelled out or not. 22 See Lødrup (2002) for some (non-colloquial) examples from Norwegian written language where til appears to be optional and Haugen (2014) for additional discussion of this variation.

23 An anonymous reviewer questions whether this should be taken to mean that the preposition $t i l$ is present syntactically, but not phonologically realized. We interpret that the preposition til is absent - both syntactically and phonologically - in these representations.

24 Partly because of the lack of research literature on the syntax of the infinitive marker te in homeland Norwegian, we are not in position to state exactly whether any of the 337 AmNo examples significantly diverge from the speech patterns of homeland Norwegian te-users. The syntactic patterns in AmNo appear to be similar to examples in the LIA corpus (cf. \$2.2), but further research is needed for detailed comparison. 25 We thank an anonymous reviewer for pointing this out to us.

26 We would also like to point out that the inheritance of dialectal forms and encroachment of English could be, and to some extent likely are, mutually reinforcing agents of change and adaptation in AmNo that are equally at play in shaping its grammar.

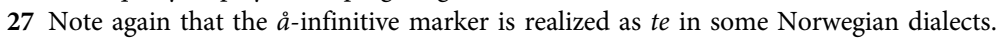

28 Although we adopt the terminology established by Ramchand \& Svenonius (2014) in this paper, the call for a tripartite division of labor in the syntactic spine has been advocated in individual theoretical work over the past four decades (Chomsky, 1981, 1986, 1995; Grohmann, 2003; van Gelderen, 2013).

29 Adopting Optimality-theoretic terminology, these sub-optimal output forms are commonly referred to as losers. The significance of losers in the formal study of language mixing has been pursued in recent years (Goldrick et al., 2016; Putnam \& Klosinski, 2020) in this framework and highlights the importance of incorporating all output forms into a unified analysis.

30 One could arguably model complementation without appealing to categorial features (as Wurmbrand \& Lohninger (to appear) suggest). In either approach, complementation is interpreted principally as a syntaxsemantics interface issue. 
31 For the current analysis we leave aside the argument of whether or not this head counts as a bounding node (or phase) and how this impact our treatment of raising in AmNo. We leave this interesting matter for future research.

32 Additionally, the low frequency in CANS of split infinitives, which are relatively commonplace in homeland Norwegian, also supports our analysis that calls for infinitive markers in $\mathrm{T}$ being highly marked in AmNo.

33 Postma (2014) analyzes the emergence of taum-infinitive as the result of a weakening of the feature specifications on T, which can also be captured via Feature Reassembly (Putnam et al., 2019) if one assumes that the strength, interpretability, and valuation status of features are vulnerable to change in these contexts. We leave these interesting possibilities for future research.

\section{References}

Aagaard, Teodor Ekblad. 2016. Doble partisipper i norsk: Verbal trekkongruens og restrukturering. Institutt for lingvistiske og nordiske studier, Universitetet i Oslo MA thesis.

Aakervik, Sylvia. 2006. Infinitivssetningens syntaks: En komparativ studie av norsk og engelsk. NTNU (Trondheim) MA thesis.

Aasen, Ivar. 1848. Det norske folkesprogs grammatik [A grammar of the language of the Norwegian people]. Christiania: Carl C. Werner and Comp.

Aasen, Ivar. 1853. Prøver af Landsmaalet i Norge [Samples of the rural language in Norway]. Christiania: Carl C. Werner and Comp.

Aboh, Enoch Oladé. 2015. The emergence of hybrid grammars: Language contact and change. Cambridge: Cambridge University Press.

Abraham, Werner. 2004. The gramamticalization of the infinitival preposition - towards a theory of 'grammaticalizing reanalysis'. Journal of Comparative Germanic Linguistics 7. 111-170.

Åfarli, Tor A. \& Kristin M. Eide. 2003. Norsk generativ syntaks. Oslo: Novus forlag.

Amaral, L \& T. Roeper. 2014. Multiple grammars and second language representations. Second Language Research 30(1). 3-36.

Arnbjörnsdóttir, Birna, Hoskuldur Thrainsson \& Iris Edda Nowenstein. 2018. V2 and V3 orders in North-American Icelandic. Journal of Language Contact 11(3). 379-412.

Arnold, Douglas \& Robert D. Borsley. 2010. Auxiliary-stranding relative clauses. In Stefan Müller (ed.), The 17th International Conference on Head-driven Phrase Structure Grammar (HPSG'09), 47-67. Stanford, CA: CSLI Publications.

Borjars, Kersti \& Kate Burridge. 2011. From preposition to purposive to infinitival marker: The Pennsylvania German fer ... zu construction. In Michael T. Putnam (ed.), Studies on German-language islands, 385-411. Amsterdam: John Benjamins.

Bousquette, Joshua \& Michael T. Putnam. 2020. Redefining language death: Evidence from moribund grammars. Language Learning 70(S1). 188-225.

Chomsky, Noam. 1981. Lectures on Government and Binding. Dordrecht: Foris.

Chomsky, Noam. 1986. Barriers. Cambridge, MA: MIT Press.

Chomsky, Noam. 1995. The minimalist program. Cambridge, MA: MIT Press.

Christensen, Ken Remshøj. 2007. The infinitive marker across Scandinavian. Nordlyd 34(1). 145-163.

Davies, William D. \& Stanley Dubinsky. 2008. The grammar of raising and control: A course in syntactic argumentation. Oxford: Blackwell.

Eide, Kristin Melum. 2011. The ghost of the Old Norse subjunctive: The Norwegian subjunctive participle. GAGL: Groninger Arbeiten zur germanistischen Linguistik 53(2). 1-28.

Eide, Kristin Melum \& Arnstein Hjelde. 2012. Vi va spost te ålær engelskt da veit du. Litt om suppose(d) og modalitet i amerikanorsk. Norsk lingvistisk tidsskrift 30. 338-364.

Faarlund, Jan T., Svein Lie \& Kjell I. Vannebo. 1997. Norsk referansegrammatikk. Oslo: Universitetsforlaget.

Faarlund, Jan Terje. 2003. Reanalyse og grammatikalisering i norske infinitivskonstruksjonar. In Jan Terje Faarlund (ed.), Språk i endring. Indre norsk språkhistorie, 57-79. Oslo: Novus.

Faarlund, Jan Terje. 2007. Parmeterization and change in non-finite complementation. Diachronica 24. $57-80$. 
Faarlund, Jan Terje. 2015. The Norwegian infinitive marker. Working papers in Scandinavian syntax 95. $1-11$.

Faarlund, Jan Terje. 2019. The syntax of Mainland Scandinavian. Oxford: Oxford University Press.

Fukuda, Shin. 2012. Aspectual verbs as functional heads: Evidence from Japanese aspectual verbs. Nautral Language \& Linguistic Theory 30. 965-1026.

van Gelderen, Elly. 2013. Clause structure. Cambridge, Cambridge University Press.

Giusti, Giuliana. 1986. On the lack of wh-infinitives with 'zu' and the projection of comp in German. Groninger Arbeiten zur Germanistischen Linguistik 28. 115-169.

Giusti, Giuliana. 1991. Zu-infinitivals and sentential structure in German. Rivista di Linguistica 3(2). 211234.

Givón, Talmy. 1980. The binding hierarchy and the typology of complements. Studies in Language 4(3). 333-377.

Goldrick, Matthew, Michael T. Putnam \& Lara S. Schwarz. 2016. Co-activation in bilingual grammars: A computational account of code mixing. Bilingualism: Language and Cognition 19(5). 857-876.

Grohmann, Kleanthes K. 2003. Prolific domains: On the anti-locality of movement dependencies. Amsterdam: John Benjamins.

Hagren, Kristina. 2008. Hur müarks infinitiven?: Infinitivkonstruktioner i svenska dialekter med fokus påinfinitivmüarket: Institutionen för nordiska språk, Uppsala universitet dissertation.

Hartsuiker, Robert J., Saskia Beerts, Maaike Loncke, Timothy Desmet \& Sarah Bernolet. 2016. Crosslinguistic structural priming in multilinguals: further evidence for shared syntax. Journal of Memory and Language 90(1). 14-30.

Haugen, Tor Arne. 2014. Adjektiv med utfyllingar: Geografisk og medial variasjon. In Janne Bondi Johannessen \& Kristin Hagen (eds.), Språk $i$ norge og nabolanda: Ny forskning om talespråk, 47-64. Oslo: Novus.

Hjelde, Arnstein. 2012. "Folkan mine, dæm bære snakka norsk" - norsk i Wisconsin frå1940-talet og fram til i dag. Norsk lingvistisk tidsskrift 30(2). 183-203.

Holmberg, Anders. 1986. Word order and syntactic features in the Scandinavian languages and English: University of Stockholm dissertation.

Hoot, Bradley. 2017. Narrow representational focus in Heritage Spanish and the syntax-discourse interface. Linguistic Approaches to Bilingualism 7(1). 63-95.

Huus, Andrea Myklebust. 2018. Distribusjonen av te som infinitivsmerke i norsk: En korpusbasert undersøkelse av utbredelsen av te som infinitivsmerke i norsk. Institutt for lingvistiske og nordiske studier, Universitetet i Oslo MA thesis.

Jarvis, Scott \& Aneta Pavlenko. 2008. Crosslinguistic infleunce in language and cognition. London: Routledge.

Johannessen, Janne Bondi. 2015. The Corpus of American Norwegian Speech. In Béata Megyesi (ed.), Proceedings of the 20th Nordic Conference of Computational Linguistics NODALIDA 2015, Vilnius: NEALT Proccedings Series 23.

Johannessen, Janne Bondi \& Signe Laake. 2012. Østnorsk som norsk fellesdialekt I Midtvesten. Norsk lingvistisk tidsskrift 30(2). 365-380.

Johnson, Kyle \& Sten Vikner. 1994. The position of the verb in Scandinavian infinitives: in $\mathrm{V}^{\mathrm{o}}$ or $\mathrm{C}^{\mathrm{o}}$ but not in $\mathrm{I}^{\mathrm{O}}$. Working papers in Scandinavian syntax 53(1). 61-84.

Kalm, Mikael. 2016. Satsekvivalenta infinitivfraser i svenskan: En synkron och diakron unders iokning: Institutionen fior nordiska språk, Uppsala universitet dissertation.

Kinn, Kari. 2020. Stability and attrition in American Norwegian nominals: a view from predicate nouns. Journal of Comparative Germanic Linguistics 23(3). 3-28.

Kühl, Karoline \& Jan Heegård Petersen. 2018. Word order in American Danish declaratives with a nonsubject initial constituent. Journal of Language Contact 11(3). 413-440.

Kupisch, Tanja. 2014. Adjective placement in simultaneous bilinguals (German-Italian) and the concept of cross-linguistic overcorrection. Bilingualism: Language and Cognition 17(1). 222-233.

Language Infrastructure Made Accessible. 2019. LIA norsk - korpus av eldre dialektopptak. www.hf.uio. no/iln/tjenester/kunnskap/sprak/korpus/talesprakskorpus/lia/index.html.

Leal, Tania, Jason Rothman \& Roumyana Slabakova. 2014. A rare structure at the syntax-discourse interface: Heritage and Spanish-dominant native speakers weigh in. Language Acquisition 21(4). 411-429.

Levine, Robert D. 2012. Auxilaries: To's company. Journal of Linguistics 48(1). 187-203. 
Lightfoot, David W. 2020. Born to parse: How children select their languages. Cambridge, MA: MIT Press.

Lindstad, Arne Martinus. 2007. Analyses of negation. Structure and interpretation: University of Oslo dissertation.

Lødrup, Helge. 2002. Infinitival complements in Norwegian and the form-function relation. In Miriam Butt \& Tracy Holloway King (eds.), Proceedings of the LFG02 Conference, 275-291. Stanford: CSLI.

Lødrup, Helge. 2008. Raising to object in Norwegian and the derived object constraint. Studia Linguistica 62(2). 155-181.

Lohndal, Terje. 2021. Syntax. In Maria Polinsky \& Silvina Montrul (eds.), The Cambridge handbook of Heritage Languages and Linguistics, 644-667. Cambridge: Cambridge University Press.

Lohndal, Terje, Jason Rothman, Tanja Kupisch \& Marit Westergaard. 2019. Heritage language acquisition: What it reveals and why it is important for formal linguistic theories. Language and Linguistics Compass 13(12). 1-19.

López, Luis. 2020. Bilingual grammar: Towards an integrated model. Cambridge: Cambridge University Press.

Louden, Mark L. 1988. Bilingualism and syntactic change in Pennsylvania German: Cornell University dissertation.

Louden, Mark L. 1997. Linguistic structure and sociolinguistic identity in Pennsylvania German society. In James R. Dow \& Michele Wol (eds.), Languages and lives: Essays in honour of Werner Enninger, 79-92. Bern: Peter Lang.

Mørck, Endre. 2019. Infinitivsmerkets status i mellomnorske kontrollkonstruksjoner. Maal og Minne 2. 101-144.

Nesse, Agnete. 2003. Written and spoken languages in Bergen in the Hansa era. In Kurt Braunmüuller \& Gisella Ferraresi (eds.), Aspects of Multilingualism in European Language History, 61-84. Amsterdam: John Benjamins.

Ojea, Ana. 2008. A feature analysis of to-infinitive sentences. Atlantis 30(1). 69-83.

Perez-Cortes, Silvia, Michael T. Putnam \& Liliana Sánchez. 2019. Differential access: Asymmetries in accessing features and building representations in heritage language grammars. Languages 4(81). 1-27.

Polinsky, Maria. 2018. Heritage languages and their speakers. Cambridge: Cambridge University Press.

Polinsky, Maria \& Greg Scontras. 2020. Understanding heritage languages. Bilingualism: Language and Cognition 23(1). 4-20.

Postma, Gertjan. 2014. A Pomeranian language island in Brazil: New syntactic data and some considerations on 'weak T'. Language Typology and Universals 67(4). 627-663.

Postma, Gertjan. 2018. A contrastive grammar of Brazilian Pomeranian. Amsterdam: John Benjamins.

Pullum, Geoffrey K. 1982. Syncategorematicity and English infinitival to. Glossa 16(2). 181-215.

Putnam, Michael T. 2020. Separating vs. shrinking. Bilingualism: Language and Cognition 23(1). 41-42.

Putnam, Michael T., Matthew Carlson \& David Reitter. 2018. Integrated, not isolated: Defining typological proximity in an integrated multilingual architecture. Frontiers in Psychology 8:2212.

Putnam, Michael T. \& Andrew D. Hoffman. 2021. Overextension in Gottscheerisch (negative) imperatives: Proclisis at the edge of the first phase. Journal of Comparative Germanic Linguistics 24(2). 185-219.

Putnam, Michael T. \& Robert Klosinski. 2020. The good, the bad, and the gradient - the role of 'losers' in code-switching. Linguistic Approaches to Bilingualism 10(1). 5-34.

Putnam, Michael T., Silvia Perez-Cortes \& Liliana Sánchez. 2019. Language attrition and the Feature Reassembly Hypothesis. In Monika S. Schmid \& Barbara Köpke (eds.), The Oxford handbook of language attrition, 18-24. Oxford: Oxford University Press.

Putnam, Michael T., Lara S. Schwarz \& Andrew D. Homan. 2021. Morphology. In Maria Polinsky \& Silvina Montrul (eds.), The Cambridge Handbook of Heritage Languages and Linguistics, 613-643. Cambridge: Cambridge University Press.

Ramchand, Gillian \& Peter Svenonius. 2014. Deriving the Functional Hierarchy. Language Sciences 46(2). 152-174.

Rinke, Ester \& Cristina Flores. 2014. Morphosyntactic knowledge of clitics by Portuguese heritage bilinguals. Bilingualism: Language and Cognition 17(4). 681-699.

Rinke, Ester, Cristina Flores \& Pilar Barbosa. 2018. Null objects in the spontaneous speech of monolingual and bilingual speakers of European Portuguese. Probus 30(1). 93-119.

Roberts, Ian. 2019. Parameter hierarchies and universal grammar. Oxford: Oxford University Press.

Sandøy, Helge. 1991. Attraksjon av supinum i færøsk og norsk. Danske folkemål 22. 252-262. 
Scontras, Gregory, Maria Polinsky \& Zuzanna Fuchs. 2018. In support of representational economy: Agreement in heritage Spanish. Glossa 3(1). 1.

Søfteland, Åshild, Michael T. Putnam \& Arnstein Hjelde. to appear. Variation in infinitive markers in American Norwegian. Proceedings of WILA 10.

Sorace, Antonella. 2011. Pinning down the concept of 'interface' in bilingualism. Linguistic Approaches to Bilingualism 1(1). 1-33.

Stechow, Arnim von \& Wolfgang Sternefeld. 1988. Bausteine syntaktischen Wissens. Opladen: Westdeutscher Verlag.

Stowell, Tim. 1982. The tense of infinitives. Linguistic Inquiry 3(13). 561-570.

Stowell, Tim. 2007. The syntactic expression of tense. Lingua 117(2). 437-463.

Stowell, Tim. 2012. Syntax. In Robert I. Binnick (ed.), The Oxford handbook of tense and aspect, 184-221. Oxford: Oxford University Press.

Strand, Bror Magnus Sviland. 2015. Infinitivsmerket i sør-rogalandsk: Ei preliminær undersøking. Presentation at MONS 16 Møte om norsk språk, Agder University Kristiansand.

Svenonius, Peter. 2021. Prepositions with CP and their implications for extended projections. Linguistic Variation 21(1): 11-45.

Travis, Lisa. 2000. The L-syntax/S-syntax boundary: Evidence from Austronesian. In Ileana Paul, Vivianne Phillips \& Lisa de Mena Travis (eds.), Formal issues in Austronesian syntax, 167-194. Dordrecht: Kluwer.

University of Bergen \& Language Council of Norway. n.d. Norsk Ordbok. http://no2014.uib.no/.

Vikner, Sten. 2020. The placement of finite verbs. In Michael T. Putnam \& B. Richard Page (eds.), The Cambridge Handbook of Germanic Linguistics, 339-364. Cambridge: Cambridge University Press.

Westergaard, Marit \& Terje Lohndal. 2019. Verb second word order in Norwegian heritage language: syntax and pragmatics. In D. Lightfoot \& J. Havenhill (eds.), Variable properties in language: their nature and acquisition, 91-102. Washington, DC: Georgetown University Press.

Wiklund, Anna-Lena. 2007. The syntax of tenselessness. Berlin: Mouton de Gruyter.

Wilder, Chris. 1988. On the German infintival marker zu and the analysis of raising constructions. Lingua 76. $115-175$.

Wurmbrand, Susanne. 2001. Infinitives: Restructuring and clause structure. Berlin: Mouton de Gruyter.

Wurmbrand, Susanne. 2014. Tense and aspect in English infinitives. Linguistic Inquiry 45(3). 403-447.

Wurmbrand, Susanne \& Christos Christopoulos. 2020. Germanic infinitives. In Michael T. Putnam \& B. Richard Page (eds.), The Cambridge handbook of Germanic linguistics, 389-412. Cambridge: Cambridge University Press.

Wurmbrand, Susanne \& Magdalena Lohninger. to appear. An implicational universal in complementation - theoretical insights and empirical progress. In Jutta M. Hartmann \& Angelika Wöllstein (eds.), Propositionale Argumente im Sprachvergleich: Theorie und Empirie, 1-50. Tübingen: Gunter Narr Verlag.

Cite this article: Putnam MT and Søfteland $\AA$ (2022). Mismatches at the syntax-semantics interface: The case of non-finite complementation in American Norwegian. Nordic Journal of Linguistics 45, 310-347. https://doi.org/10.1017/S033258652100010X 